\title{
Infiltration and sealing for managing non-cavitated proximal lesions: a systematic review and meta-analysis
}

Yuanyuan Chen ${ }^{1,3,4}$, Dongru Chen ${ }^{2,3,4}$ and Huancai Lin 1,3,4* (D)

\begin{abstract}
Background: Infiltration and sealing are micro-invasive treatments for arresting proximal non-cavitated caries lesions; however, their efficacies under different conditions remain unknown. This systematic review and meta-analysis aimed to evaluate the caries-arresting effectiveness of infiltration and sealing and to further analyse their efficacies across different dentition types and caries risk levels.

Methods: Six electronic databases were searched for published literature, and references were manually searched. Split-mouth randomised controlled trials (RCTs) to compare the effectiveness between infiltration/sealing and non-invasive treatments in proximal lesions were included. The primary outcome was obtained from radiographical readings.

Results: In total, 1033 citations were identified, and 17 RCTs (22 articles) were included. Infiltration and sealing reduced the odds of lesion progression (infiltration vs. non-invasive: $\mathrm{OR}=0.21,95 \% \mathrm{Cl} 0.15-0.30$; sealing vs. placebo: $\mathrm{OR}=0.27,95 \% \mathrm{Cl} 0.18-0.42$ ). For both the primary and permanent dentitions, infiltration and sealing were more effective than non-invasive treatments (primary dentition: $\mathrm{OR}=0.30,95 \% \mathrm{Cl} 0.20-0.45$; permanent dentition: $\mathrm{OR}=0.20$, $95 \% \mathrm{Cl}$ 0.14-0.28). The overall effects of infiltration and sealing were significantly different from the control effects based on different caries risk levels $(O R=0.20,95 \% \mathrm{Cl} 0.14-0.28)$. Except for caries risk at moderate levels (moderate risk: $\mathrm{OR}=0.32,95 \% \mathrm{Cl} 0.01-8.27$ ), there were significant differences between micro-invasive and non-invasive treatments (low risk: $\mathrm{OR}=0.24,95 \% \mathrm{Cl} 0.08-0.72$; low to moderate risk: $\mathrm{OR}=0.38,95 \% \mathrm{Cl} 0.18-0.81$; moderate to high risk: $\mathrm{OR}=0.17,95 \% \mathrm{Cl} 0.10-0.29$; and high risk: $\mathrm{OR}=0.14,95 \% \mathrm{Cl} 0.07-0.28$ ). Except for caries risk at moderate levels (moderate risk: $\mathrm{OR}=0.32,95 \% \mathrm{Cl} 0.01-8.27$ ), infiltration was superior (low risk: $\mathrm{OR}=0.24,95 \% \mathrm{Cl} 0.08-0.72$; low to moderate risk: $\mathrm{OR}=0.38,95 \% \mathrm{Cl} 0.18-0.81$; moderate to high risk: $\mathrm{OR}=0.20,95 \% \mathrm{Cl} 0.10-0.39$; and high risk: $\mathrm{OR}=0.14,95 \% \mathrm{Cl}$ 0.05-0.37).
\end{abstract}

Conclusion: Infiltration and sealing were more efficacious than non-invasive treatments for halting non-cavitated proximal lesions.

Keywords: Infiltration, Sealing, Non-cavitated proximal lesions

*Correspondence: linhc@mail.sysu.edu.cn

${ }^{3}$ Department of Preventive Dentistry, Hospital of Stomatology, Guanghua

School of Stomatology, Sun Yat-Sen University, Guangzhou, China

Full list of author information is available at the end of the article

\begin{abstract}
Introduction
Dental caries is one of the most prevalent oral diseases worldwide [1]. In terms of the susceptibility of the tooth surface to cavitation, the proximal zones have a high risk of being carious [2]. Early proximal caries lesions are prevalent but difficult to observe. Traditionally, invasive
\end{abstract}

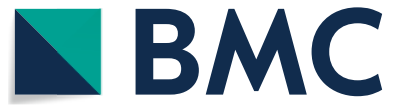

(c) The Author(s) 2021. Open Access This article is licensed under a Creative Commons Attribution 4.0 International License, which permits use, sharing, adaptation, distribution and reproduction in any medium or format, as long as you give appropriate credit to the original author(s) and the source, provide a link to the Creative Commons licence, and indicate if changes were made. The images or other third party material in this article are included in the article's Creative Commons licence, unless indicated otherwise in a credit line to the material. If material is not included in the article's Creative Commons licence and your intended use is not permitted by statutory regulation or exceeds the permitted use, you will need to obtain permission directly from the copyright holder. To view a copy of this licence, visit http://creativecommons.org/licenses/by/4.0/. The Creative Commons Public Domain Dedication waiver (http://creativeco mmons.org/publicdomain/zero/1.0/) applies to the data made available in this article, unless otherwise stated in a credit line to the data. 
treatment methods (drill and fill) have been applied; however, these methods require the removal of marginal tissue and can weaken the strength of the residual tooth structure [3]. In recent years, non-invasive or microinvasive treatments have been developed to replace traditional restorative treatments. These treatment protocols aim to restore the sound structure in a more preventive way, reduce associated pain and costs, and regain function and aesthetics [4-7]

Non-invasive treatments manage caries lesions via mechanical removal of the biofilm, dietary control or remineralisation treatments [8]. Removal of the biofilm, such as by toothbrushing and interdental flossing, together with dietary control, focused on prevention rather than halting carious lesions $[8,9]$. Remineralisation of the enamel lesion with fluoride and casein phosphopeptide amorphous calcium phosphate (CPP-ACP) is promising $[7,10,11]$, but it lacks validity without good compliance $[7,12]$. Consequently, micro-invasive treatments have been developed as alternatives since they are less dependent upon patient compliance and are more conservative than invasive treatments.

Micro-invasive treatments are applied to manage the lesions confined to the outer third of dentin. They involve the preliminary treatment of the tooth surface. Operators frequently use a conditioning step via organic acid, and micrometres of the enamel layer are removed [13, 14]. The intact surface of the carious lesions is preserved.

Infiltration and sealing are frequently used as microinvasive treatments. Recently, infiltration technology has been performed clinically for non-cavitated proximal caries $[15,16]$. This technique uses low-viscosity resin to occlude the micropores of non-cavitated proximal carious lesions [16, 17]. Based on the capillary force, resin penetrates into the pores of demineralized enamel and establishes a barrier to impede acid diffusion [18, 19]. Thus, micro-porosities are filled, and light scattering of the lesions turns out to be similar to the sound enamel [12]. At the same time, sealing has been investigated to efficiently arrest lesion progression in vivo and in vitro [20-22]. The procedure of sealing involves the application of a resin sealant, glass ionomer cement (GIC), polyurethane tape or adhesives after tooth separation [23-28]. Operators use acid to increase the roughness and afterwards increase the micro-mechanical retention. Resin-based and GIC based sealants are the most commonly used today [29]. They can be light cured to form a layer and impede the invasion of bacteria. In addition, compared to the traditional sealants, polyurethane tapes are regarded as more convenient and easier to handle [23, 24].

Previous systematic reviews and meta-analyses have shown that micro-invasive treatments are more effective than non-invasive treatments [3,13, 15, 30-32]. However, there is still uncertainty about the intervention effects for patients with different dentition types and different caries risk levels since there have not been sufficient cases to reach a conclusion [15]. Generally, caries management with prevention or therapeutic protocols is based on the caries risk [33]. Thus, to assist in a treatment plan, it is meaningful to justify the intervention effects based on different caries risk levels. In addition, the structure of primary teeth is different from that of the permanent teeth. The thinner and less mineralisation of enamel layer, as well as broader contact area, has a greater likelihood for caries in primary dentition. Researchers found that there was a higher risk of failure in primary teeth with conventional restoration treatments $[8,34,35]$. Thus, whether micro-invasive treatments would influence progression, especially in the primary dentition, would be of great importance for future application. Furthermore, the latest trials are needed to obtain sufficient evidence qualitatively and quantitatively. Therefore, in this study, we conducted a systematic review and meta-analysis to evaluate the efficacies of infiltration and sealing on proximal caries lesions and analysed their efficacies based on different dentition types and caries risk levels.

\section{Methods}

This study was conducted according to the PRISMA statement $[36,37]$. The protocols of the eligibility criteria, search strategy, data extraction, risk of bias assessment in the included studies, data synthesis and statistical analysis were prepared.

\section{Eligibility criteria}

The eligibility criteria were designed in accordance with the PICOS strategy.

Population (P): Children, adolescents and adults, with proximal or approximal non-cavitated caries, presumed clinically (visually intact surface) or by radiographs.

Interventions (I): Infiltration or sealing technology. Comparisons $(\mathrm{C})$ : The two micro-invasive strategies were compared to each other and against non-invasive treatments (placebo or no treatment).

Outcomes $(\mathrm{O})$ : Lesion progression was assessed by digital radiography via digital subtraction radiography (DSR), pairwise reading or lesion stage.

Study design (S): Split-mouth randomised controlled trials (RCTs).

Reviews and meta-analyses, in situ studies, in vitro studies, case reports, study protocols, and meeting abstracts were excluded. Articles were excluded if the patients had 
a mixture of caries risk levels or if they had high and low caries risk without a specific distribution. Only studies with caries risk for most people (more than $80 \%$ ) were collected for further classification.

\section{Search}

Electronic databases (Cochrane Library, PubMed, Embase, OpenGrey, ProQuest Dissertations \& Theses Global, and Web of Science Conference Proceedings Citation Index-Science (CPCI-S)-2000) were searched by Y.C. and D.C. from inception to April 6, 2020. Two authors (Y.C. and D.C.) selected the eligible studies independently, and disagreements were resolved by discussion and consultation with a third person (H.L.). Eligible studies were explored without limitations on publication type, language, year and region. The following terms were used to search the title, abstract, keywords or $\mathrm{MeSH}$ terms: "tooth demineralization OR tooth decay OR caries OR lesion" and "seal OR sealant OR sealing OR infiltrate OR infiltration" and "proximal OR approximal" ("Appendix 1"). A manual search was an auxiliary strategy to improve the comprehensiveness of retrieving studies. Studies were imported into EndNote software, version X9. Duplicates were excluded, and the full texts of the eligible retrieved studies were assessed. Data were requested from authors of the original studies if necessary.

\section{Data extraction}

Data extraction was performed and recorded by two calibrated reviewers independently and in duplicate (Y.C. and D.C.), and disputes were settled by discussion. The titles and abstracts of the studies were initially examined to eliminate irrelevant studies, and then the full texts of the retrieved studies were screened to obtain the included studies. The extracted data included study details (first author and year of publication), patient information (age, sample size, sample type, drop-out rate and caries risk), study design, inventions, and outcome data (caries progression).

\section{Assessment of risk of bias in the included studies}

The risk of bias of the included studies was evaluated according to the criteria in the Cochrane Collaboration's Risk of Bias Tool (RoB 2) [38]. Researchers must answer signalling questions as follows: bias arising from the randomisation process, bias due to deviations from intended interventions, bias due to missing outcome data, bias measurement of the outcome, bias in selection of the reported result. In addition, drop-out rates less than $25 \%$ were regarded to have no substantial impacts of the failure based on previous studies $[13,31]$. Overall risk of bias judgement is shown: trials with at least 1 item regarded as high risk were identified as having a high risk of bias. Trials with some concerns in 1 or more key domains were identified as having some concerns about risk. Trials with a low risk of bias in all aspects were identified as having a low risk of bias.

\section{Heterogeneity assessment}

We assessed clinical, methodological diversity and statistical heterogeneity according to the Cochrane Handbook [39]. Clinical heterogeneity involves in the differences among populations, interventions and outcomes. Methodological heterogeneity is associated with the study designs and quality of the studies. Statistically heterogeneity was assessed using a $\mathrm{Chi}^{2}$ or $I^{2}$ test. Only when the studies have clinical and methodological homogeneity are researchers suggested to have assessment based on statistical heterogeneity.

\section{Summary measures and data synthesis}

The meta-analysis was conducted using Stata software, version 16 . Effect variables were calculated as odds ratios (ORs) with $95 \%$ confidence intervals (95\% CIs) for binary data in this research. Meta-regression analysis was conducted to identify the influence of follow-up years on treatment efficacy.

We conducted the meta-analysis with a random-effects model owing to clinical issues and methodological heterogeneity, regardless of the statistical assessment. The $\mathrm{t}^{2}$ was used to assess statistical heterogeneity. Since differences among the invention methods, dentition types and caries risk levels might have affected the outcome data, we individually analysed these factors using subgroup analysis with a random-effects empirical Bayes model.

\section{Risk of bias across studies}

Publication bias should be considered if more than 10 studies with clinical, methodological and statistical homogeneity are included. Egger's test and Begg's test can be used to evaluate publication bias.

\section{Quality of the evidence}

The overall quality of the accrued evidence was assessed with the Grading of Recommendations Assessment, Development and Evaluation (GRADE) [40, 41]. According to GRADE, the evidence was graded as high, moderate, low and very low. High quality indicates high reliability of the estimate. Moderate quality indicates that further research would have an effect on the estimate. Low and very low quality indicate that the true effect could differ from the estimate of the effect. Assessment items were risk of bias, inconsistency, indirectness, imprecision and other considerations (publication bias). We could downgrade one or two levels due to serious or 
very serious risk of the five domains. In this study, the quality of the evidence was evaluated using GRADEpro (online software).

\section{Results}

\section{Study selection}

A total of 1033 citations were initially identified after an electronic database search (1032 articles) and a manual search ( 1 article). The selection process was presented as a flow diagram (Fig. 1). Ultimately, 22 articles of the 17 latest studies were included (Tables $1 \mathrm{a}, \mathrm{b}$ and 2 ), of which 9 articles were related to 4 different series of studies and
1 article compared infiltration and sealing to the control group individually [23-28, 42-57].

\section{Characteristics of the included studies}

The data from included studies were summarised in Tables 1 and 2. All of the studies were split-mouth RCTs. A total of 830 patients (ranging from 4.6 to 45 years old) were enrolled in 17 clinical trials. There were 2124 noncavitated proximal lesions in the trials. A total of 5 studies were included that assessed lesions in the primary dentition [27, 42, 45-48], and 12 studies assessed lesions in the permanent dentition [23-26, 28, 43, 44, 49-57].

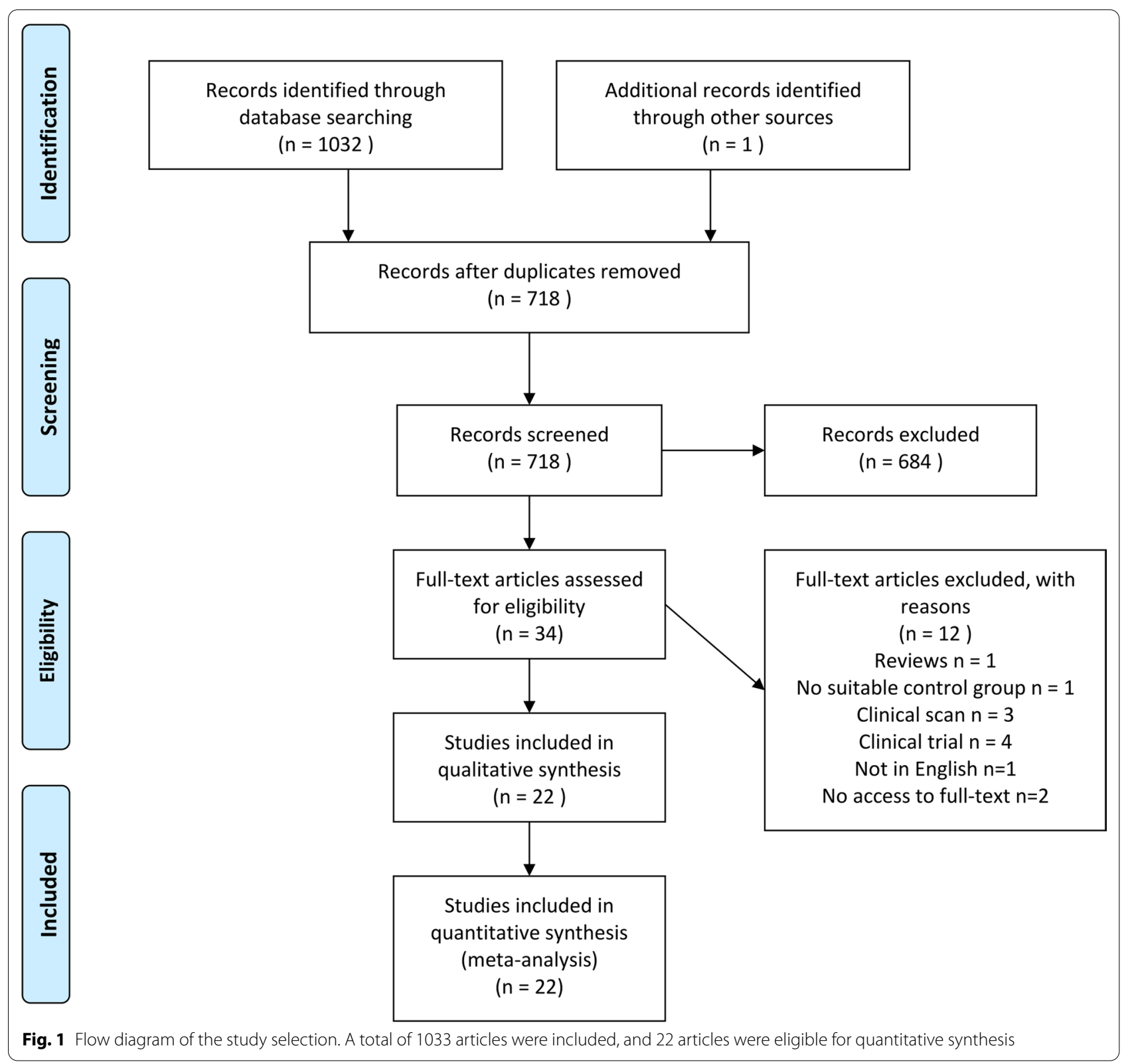




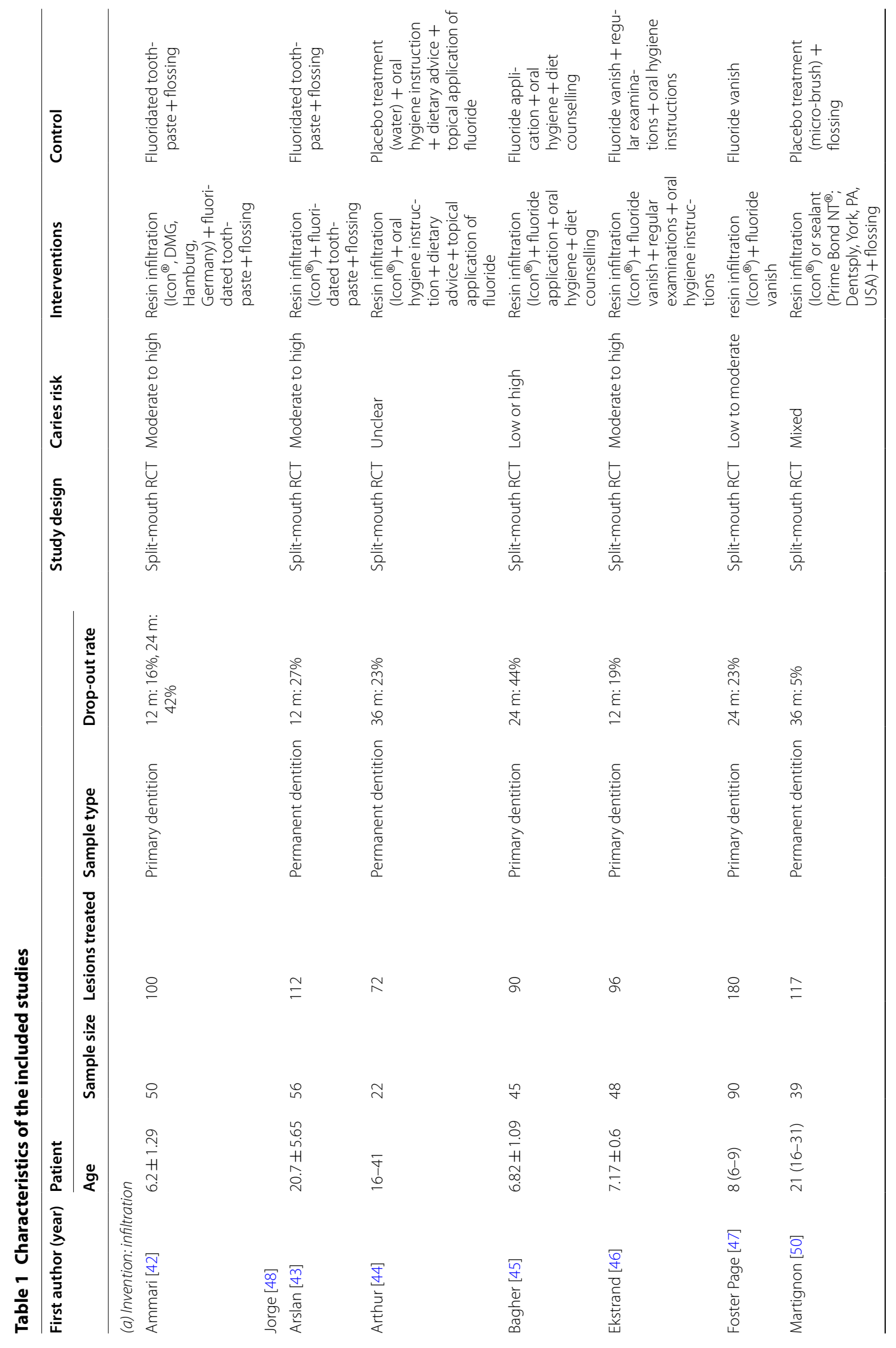




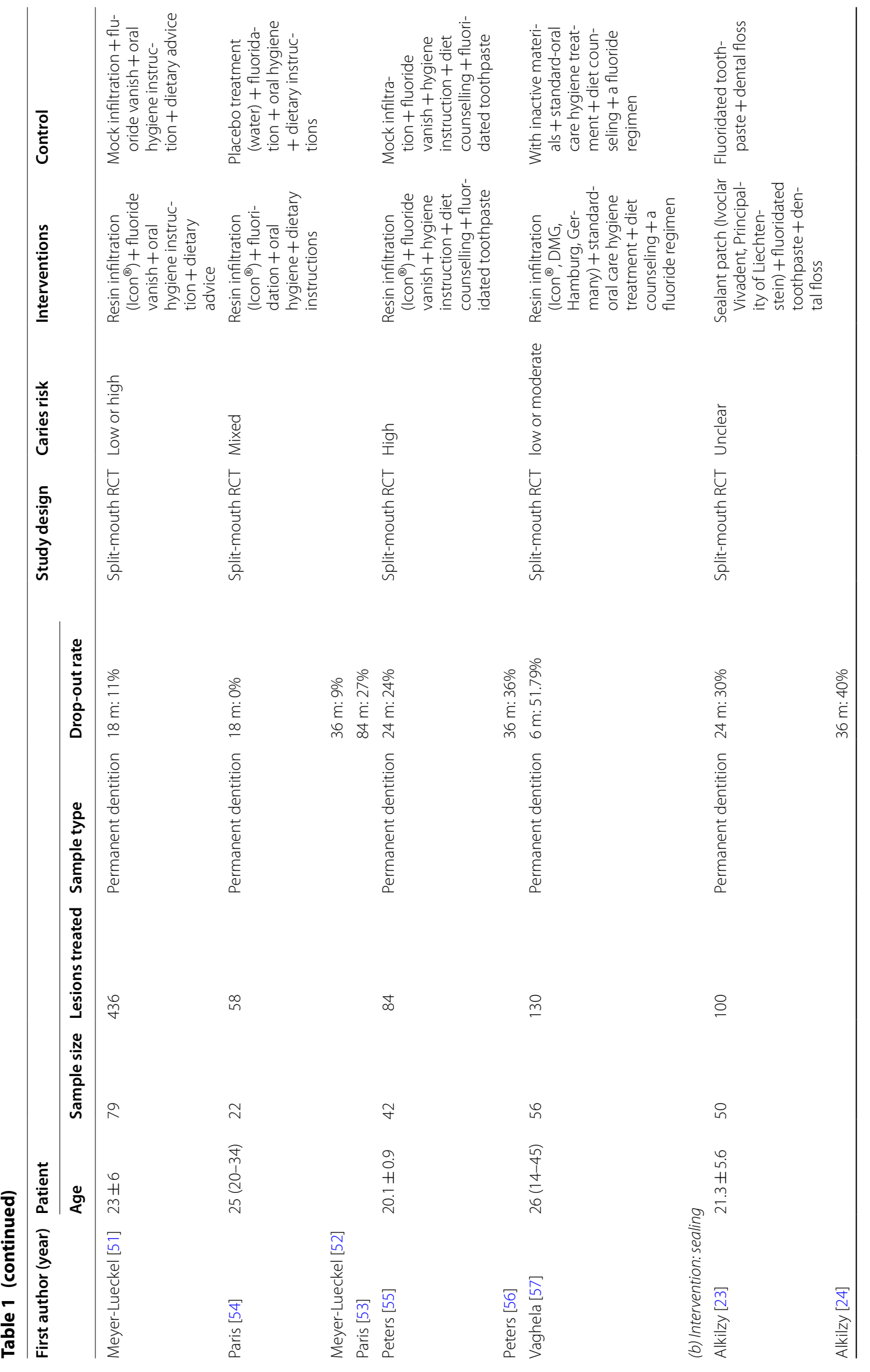




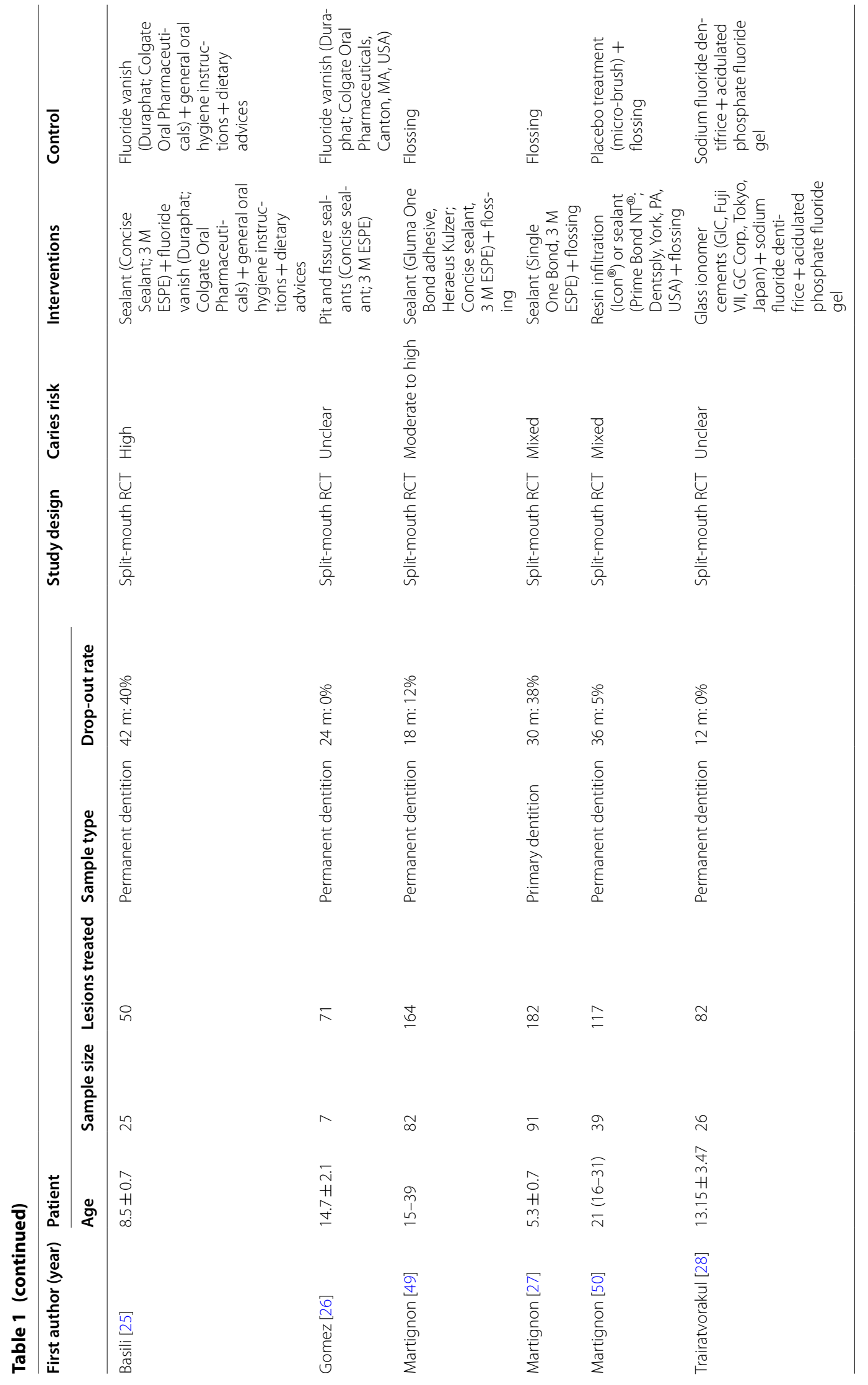


Table 2 Caries progression of included studies

\begin{tabular}{|c|c|c|c|c|c|c|}
\hline \multirow[t]{2}{*}{ First author (year) } & \multirow[t]{2}{*}{ Assessment } & \multirow{2}{*}{$\begin{array}{l}\text { Follow-up } \\
\text { (months) }\end{array}$} & \multicolumn{2}{|l|}{ Test group } & \multicolumn{2}{|c|}{ Control group } \\
\hline & & & Progression & Total & Progression & Total \\
\hline Alkilzy [23] & Independent reading & 24 & 2 & 35 & 2 & 35 \\
\hline \multicolumn{7}{|l|}{ Alkilzy [24] } \\
\hline & & 36 & 2 & 30 & 2 & 30 \\
\hline Arthur [44] & Pairwise reading & 36 & 2 & 27 & 5 & 27 \\
\hline Arslan [43] & DSR & 12 & 1 & 45 & 9 & 45 \\
\hline Ammari [42] & Pairwise reading & 12 & 5 & 42 & 14 & 42 \\
\hline \multicolumn{7}{|l|}{ Jorge [48] } \\
\hline & & 24 & 7 & 29 & 16 & 29 \\
\hline \multirow[t]{4}{*}{ Bagher [45] } & Pairwise reading & 6 & 5 & 44 & 7 & 44 \\
\hline & & 12 & 6 & 41 & 13 & 41 \\
\hline & & 18 & 7 & 31 & 13 & 31 \\
\hline & & 24 & 10 & 25 & 18 & 25 \\
\hline Basili [25] & Pairwise reading & 42 & 3 & 15 & 8 & 15 \\
\hline Ekstrand [46] & Independent reading & 12 & 9 & 39 & 24 & 39 \\
\hline Foster Page [47] & Pairwise reading & 12 & 15 & 66 & 30 & 69 \\
\hline Gomez [26] & Independent reading & 24 & 3 & 38 & 4 & 33 \\
\hline \multirow[t]{3}{*}{ Martignon [49] } & Independent reading & 18 & 7 & 72 & 19 & 72 \\
\hline & Pairwise reading & & 16 & 72 & 34 & 72 \\
\hline & DSR & & 30 & 69 & 58 & 69 \\
\hline \multirow[t]{2}{*}{ Martignon [27] } & Independent reading & 12 & 20 & 73 & 37 & 73 \\
\hline & & 30 & 26 & 56 & 40 & 56 \\
\hline \multirow[t]{8}{*}{ Martignon [50] } & Pairwise reading & 12 & Infiltration: 6 & 38 & 18 & 38 \\
\hline & & & Sealing: 11 & & & \\
\hline & & 24 & Infiltration: 9 & 37 & 23 & 37 \\
\hline & & & Sealing: 15 & & & \\
\hline & & 36 & Infiltration: 12 & 37 & 26 & 37 \\
\hline & & & Sealing: 15 & & & \\
\hline & DSR & 12 & Infiltration: 10 & 38 & 24 & 38 \\
\hline & & & Sealing: 16 & & & \\
\hline Meyer-Lueckel [51] & Pairwise reading & 18 & 10 & 186 & 58 & 186 \\
\hline Paris [54] & Independent reading & 18 & 1 & 27 & 2 & 27 \\
\hline \multicolumn{7}{|l|}{ Meyer-Lueckel [52] } \\
\hline \multicolumn{7}{|l|}{ Paris [53] } \\
\hline & Pairwise reading & 18 & 1 & 27 & 6 & 27 \\
\hline & DSR & 18 & 2 & 27 & 10 & 27 \\
\hline & Pairwise reading & 36 & 1 & 26 & 9 & 26 \\
\hline & DSR & 36 & 1 & 26 & 11 & 26 \\
\hline & Pairwise reading & 84 & 1 & 22 & 9 & 22 \\
\hline & DSR & 84 & 2 & 22 & 10 & 22 \\
\hline Peters [55] & Independent reading & 24 & 0 & 34 & 3 & 34 \\
\hline \multicolumn{7}{|l|}{ Peters [56] } \\
\hline & Pairwise reading & 24 & 1 & 34 & 9 & 34 \\
\hline & Independent reading & 36 & 3 & 29 & 7 & 29 \\
\hline & Pairwise reading & 36 & 4 & 29 & 14 & 29 \\
\hline Trairatvorakul [28] & Pairwise reading & 12 & 0 & 41 & 3 & 41 \\
\hline Vaghela [57] & Pairwise reading & 6 & 0 & 30 & 3 & 30 \\
\hline
\end{tabular}


The interventions included resin infiltration (11 studies) [42-48, 50-57] and sealant (7 studies) [23-28, 49, 50]. The follow-up duration ranged from 6 to 84 months. In terms of caries risk levels, 2 studies reported high risk $[25,55,56], 4$ studies reported moderate to high risk [42, $43,46,48,49]$, 1 study reported low to moderate risk [47], 1 study reported low or moderate risk [57], 2 studies reported low or high risk [45, 51], 3 studies reported mixed risk levels [27, 50, 52-54] and 4 studies did not report caries risk in the articles [23, 24, 26, 28, 44]. Five caries risk statuses were included in the subgroup analysis: low [51, 57], low to moderate [47], moderate [57], moderate to high $[42,43,46,48,49]$ and high $[25,51,55$, 56]. All of the trials used radiographic lesion progression as the primary outcome. Methods for evaluating lesion progression included independent reading of radiographs, pairwise reading of radiographs and DSR. For data analysis, the most sensitive outcome was recorded if two or more evaluation methods were used in a study (outcomes obtained by DSR $>$ pairwise reading $>$ independent reading).

\section{Risk of bias within studies}

The risk of bias within studies was summarised in Figs. 2 and 3. Except for 3 studies with unclear risk for randomisation process due to unbalanced distribution of lesions at baseline $[49,52-54,57]$, the remaining studies all had a low risk of bias [23-26, 28, 42-51]. Eight studies had some concerns due to deviations from intended interventions [26, 28, 44, 46, 47, 49-51] while 8 studies have high risk [23-25, 27, 43, 45, 52-54, 57] and 1 study has low risk $[55,56]$. All of the studies had low risk for bias due to missing outcome data, measurement of the outcomes and selection of the reported results.

\section{Heterogeneity assessment}

For clinical heterogeneity, sealing and infiltration were two types of invention treatments enrolled as microinvasive treatments. For non-invasive treatments, it differed across studies. Five studies had placebo treatments, while flossing, fluoride application and dietary advice were also set as comparators. Further, in different studies, these comparators were not combined totally and consistently. Independent reading, pairwise reading, and DSR were used as outcome assessments and varied in studies. In addition, results of bias due to deviations from intended interventions turned out to be due to inconsistency in methodological assessments. No statistical heterogeneity was found between studies $\left(\tau^{2}=0\right)$.

\section{Meta-regression analysis}

The meta-regression analysis results revealed that different research durations (ranging from 6 to 84 months) did not influence caries progression $(\mathrm{P}>|\mathrm{t}|: 0.620,95 \% \mathrm{CI}$ -0.143 to 0.233 ). Thus, we chose caries progression at the longest follow-up times for continuous RCTs, similar to previous reviews $[3,13,30]$.

\section{Efficacy of infiltration and sealing for non-cavitated proximal caries}

Seventeen RCTs were enrolled to assess the efficacy of infiltration and sealing for non-cavitated proximal caries. A random-effects model was used even though there was no significant statistical heterogeneity between

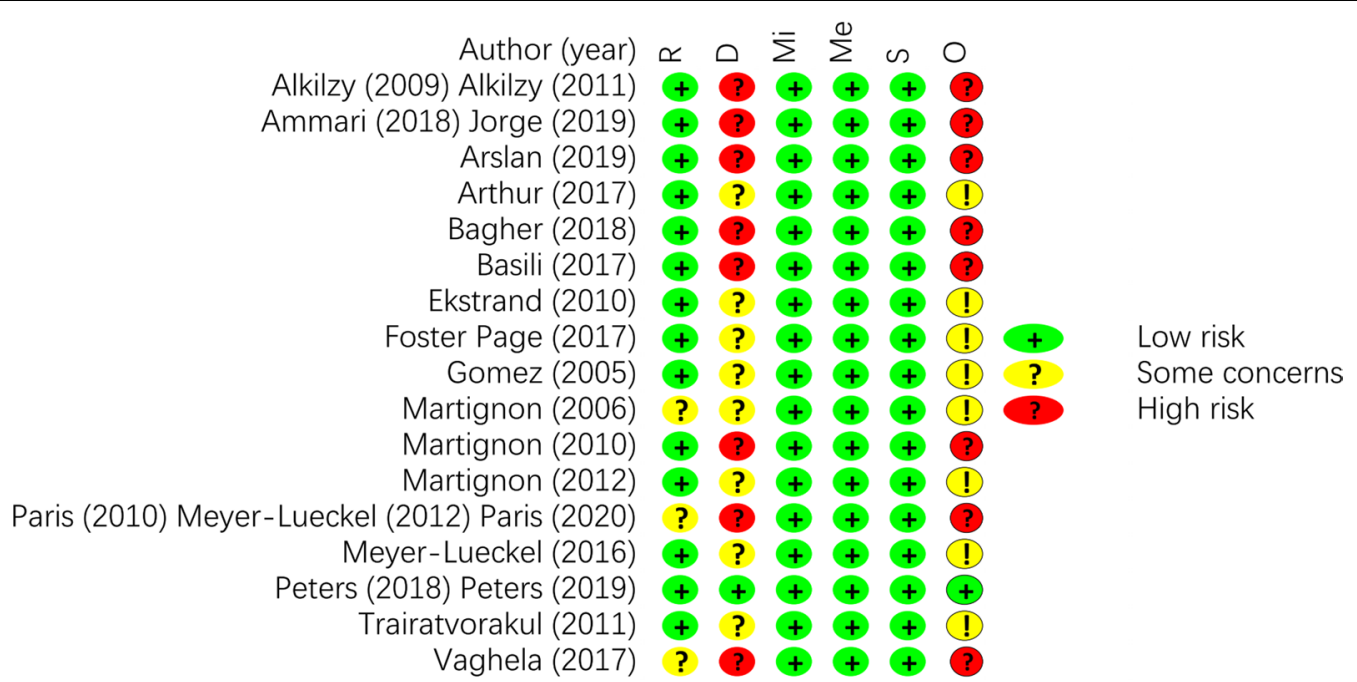

Fig. 2 Risk of bias summary of the included studies. In this chart, green circles represent a low risk of bias, yellow circles represent some concerns of bias, and red circles represent a high risk of bias 


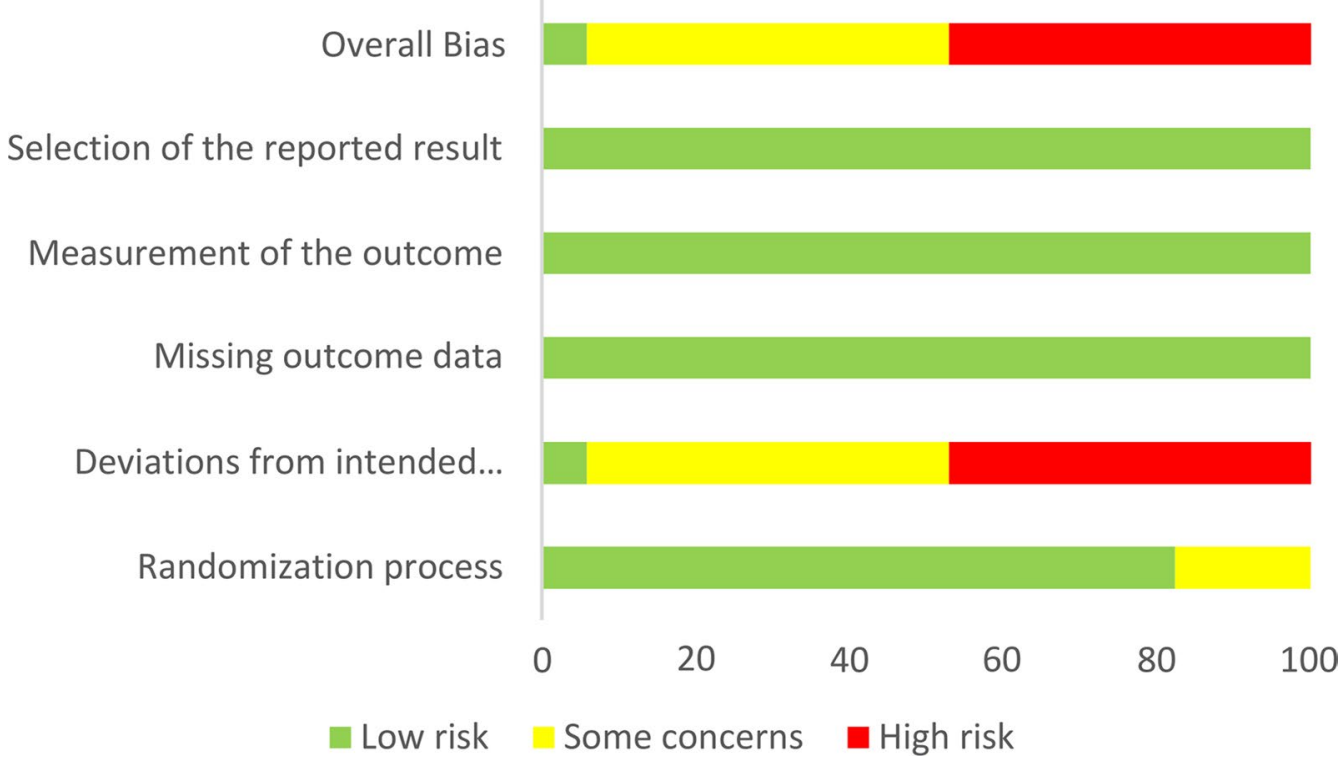

Fig. 3 Risk of bias graph. In this graph, green bars represent a low risk of bias, yellow bars represent some concerns of bias, and red bars represent a high risk of bias

studies $\left(\tau^{2}=0.00\right.$, Fig. 4). The overall intervention effects of infiltration and sealing were significantly different from the intervention effects of the control treatment $(\mathrm{OR}=0.23,95 \%$ CI $0.18-0.30)$. We analysed the two different measures (infiltration and sealing) using subgroup analysis, and we found that both invention measures reduced the odds of lesion progression compared with the control group (infiltration vs. non-invasive treatments: $\mathrm{OR}=0.21,95 \% \mathrm{CI} 0.15-0.30$; sealing vs. placebo: $\mathrm{OR}=0.27,95 \%$ CI $0.18-0.42$ ).

Seventeen RCTs were related to infiltration and sealing of primary dentition or permanent dentition. There was no significant statistical heterogeneity of the included RCTs $\left(\tau^{2}=0.00\right.$, Fig. 5). Non-cavitated proximal lesions were reduced when measures were undertaken in the primary dentition and permanent dentition (primary dentition: $\mathrm{OR}=0.30,95 \% \mathrm{CI} 0.20-0.45$; permanent dentition: $\mathrm{OR}=0.20,95 \%$ CI 0.14-0.28, Fig. 5).

Nine RCTs were analysed for the efficacy of infiltration and sealing at different caries risk levels (Table 1a, b). There was no significant statistical heterogeneity among the nine RCTs $\left(\tau^{2}=0.00\right.$, Fig. 6$)$. The overall effects of infiltration and sealing were significantly different from the overall effects of control treatment $(\mathrm{OR}=0.20$, 95\% CI 0.14-0.28). For patients with different caries risk levels, there were significant differences between micro-invasive treatments and non-invasive treatments (low risk: $\mathrm{OR}=0.24,95 \%$ CI $0.08-0.72$; low to moderate risk: $\mathrm{OR}=0.38,95 \% \mathrm{CI} 0.18-0.81$; moderate to high risk: $\mathrm{OR}=0.17,95 \%$ CI $0.10-0.29$; and high risk: $\mathrm{OR}=0.14,95 \% \mathrm{CI} 0.07-0.28)$ except for moderate risk: $(\mathrm{OR}=0.32,95 \% \mathrm{CI} 0.01-8.27)$. Seven RCTs were related to infiltration at different caries risk levels. There was no significant statistical heterogeneity among the seven RCTs $\left(\tau^{2}=0.00\right.$, Fig. 7). In contrast to patients with moderate caries risk (OR $=0.32,95 \%$ CI $0.01-8.27)$, significant differences in the progression rate were found among patients who were treated with infiltration and non-invasive treatments (low risk: $\mathrm{OR}=0.24,95 \% \mathrm{CI}$ $0.08-0.72$; low to moderate risk: $\mathrm{OR}=0.38,95 \% \mathrm{CI} 0.18$ 0.81 ; moderate to high risk: $\mathrm{OR}=0.20,95 \% \mathrm{CI} 0.10-0.39$; and high risk: $\mathrm{OR}=0.14,95 \% \mathrm{CI} 0.05-0.37$ ). Two RCTs were related to sealing across different caries risk levels. Due to insufficient patient information in terms of caries risk levels in the sealing group, no subgroup analysis was conducted.

\section{Publication bias}

For this meta-analysis, publication bias was not evaluated due to insufficient studies (fewer than 10) with clinical and methodological homogeneity.

\section{Quality of evidence}

Based on this study, infiltration or sealing arrested progression in 283 lesions per 1000 treated lesions. Infiltration arrested progression in 275 lesions per 1000 treated lesions. Sealing arrested progression in 288 lesions per 1000 treated lesions. It was downgraded one level 


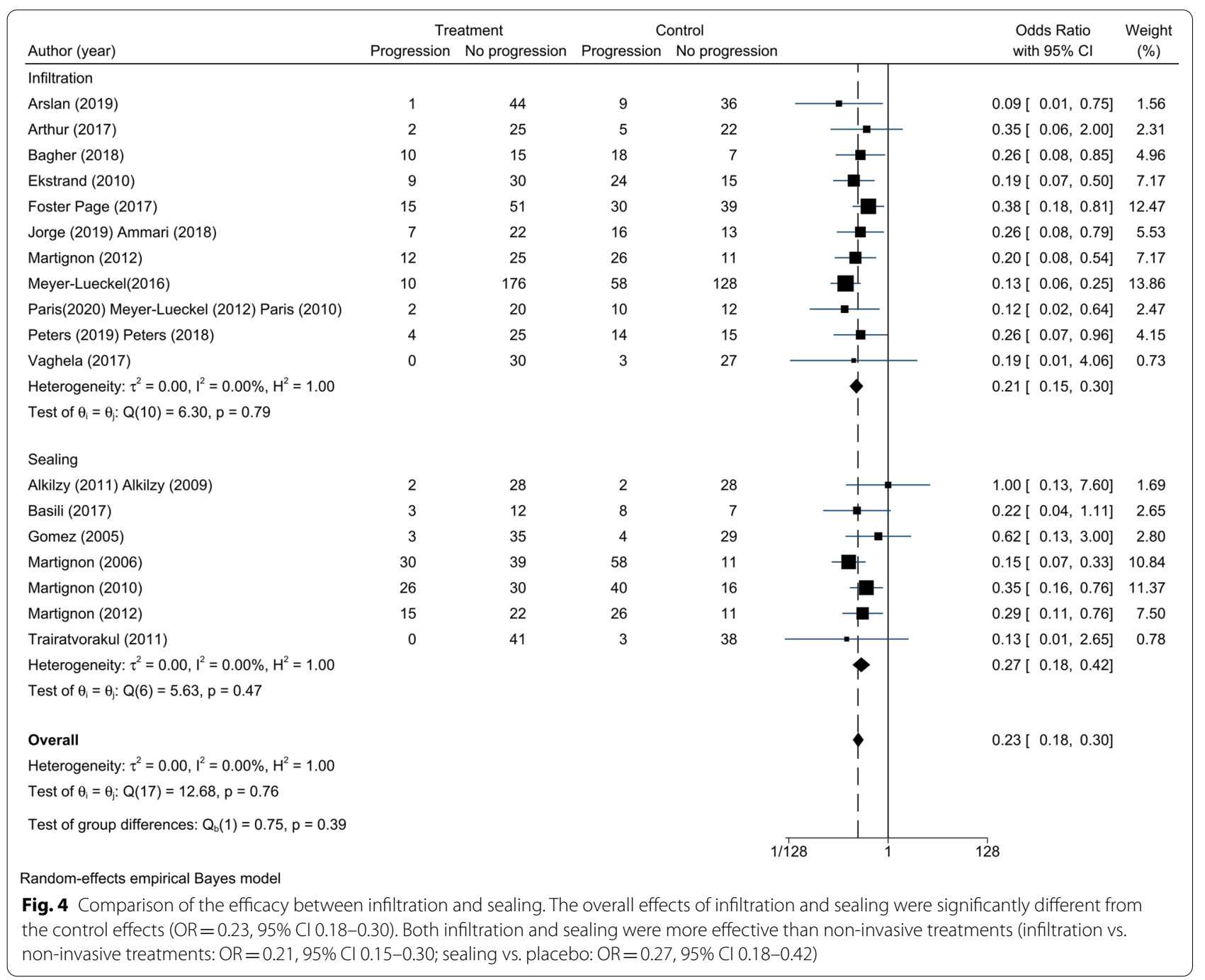

mainly owing to a high risk of bias in half of the included studies. All of the evidence was graded as moderate ("Appendix 2").

\section{Discussion}

Micro-invasive inventions represent promising approaches for treating proximal lesions. Based on this study, infiltration and sealing can be considered effective micro-invasive inventions for halting the progression of non-cavitated proximal caries. These results were consistent with previous studies [3, 15, 32]. Based on GRADEpro, all of the included studies led to a moderate quality of evidence. We downgraded the quality due to the high risk of bias when evaluating the deviations from intended interventions. In addition, a small proportion of included studies (three studies) had unclear risk for randomisation process due to unbalanced distribution of lesions at baseline, but we did not downgrade the quality again since overall high risk of bias in two studies were already evaluated. As for the inconsistency, there was no statistical heterogeneity between studies; thus we did not downgrade the quality. The publication bias was not evaluated due to a lack of sufficient studies, and we did not downgrade. Therefore, the conclusions from this research are robust and reliable.

With this limited research, our study could not identify a superior micro-invasive treatment for clinical application. Nevertheless, a comparison of infiltration and sealing in terms of clinical procedure could be performed. Infiltration is considered simple and acceptable for patients [42, 47, 58]. After the application of topical anaesthesia to reduce pain and the placement of the wedge, the resin penetrated the proximal lesions, and only one visit was needed for application [32, 47, 55, 56]. Comparatively, sealing is more complex than infiltration since it requires two visits [23-27]. In addition, 


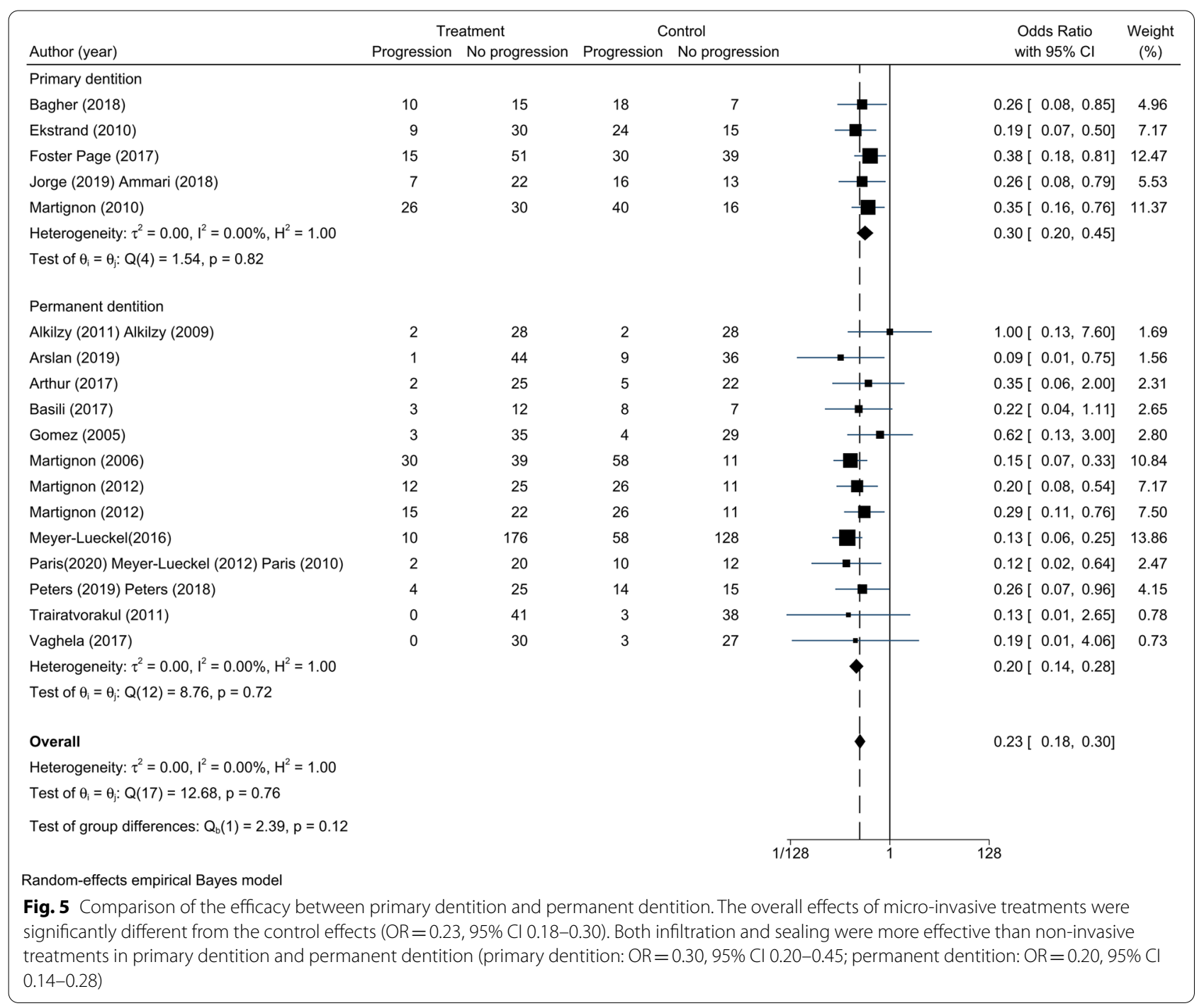

the commercial product "Icon" is available for standard application in resin infiltration [32]. Thus, with regard to clinical application, infiltration seems to be more suitable. Moreover, a network meta-analysis revealed that infiltration is more likely to be effective than sealing [32]. Conversely, an in vitro study showed that sealing might be more effective in preventing enamel dissolution [59], and the remaining roughness and micro-leakage after infiltration could cause plaque accumulation and biofilm formation [59-63]. Therefore, resolving these disputes requires further trials to directly compare the efficiency, applicability and cost between infiltration and sealing [32].

Based on this research, and according to subgroup analysis, infiltration and sealing are appliable regardless of dentition type. Currently, only one study has concluded that sealing is effective at halting lesion progression both in the primary dentition and the permanent dentition [30]. In other meta-analyses, due to a lack of sufficient data, no robust conclusions could be drawn regarding primary teeth [15]. Although trials for primary teeth seem to be more complicated, and it is more difficult to ensure proper controls, investigations into the efficacy of micro-invasive treatments for primary teeth are necessary and meaningful. Specifically, comfort and acceptability during the treatment of primary teeth are worth evaluating [42, 47]. Furthermore, follow-up times are limited to more than 24 months for primary dentition due to the exfoliation of primary teeth. For 5 studies enrolled in this research, we could conclude that micro-invasive treatments were more effective than non-invasive treatments in the primary dentition for the period from 12 to 24 months. Thus, there are new insights into the treatment of non-cavitated proximal caries in primary teeth since microinvasive treatments not only reduce children's pain and 


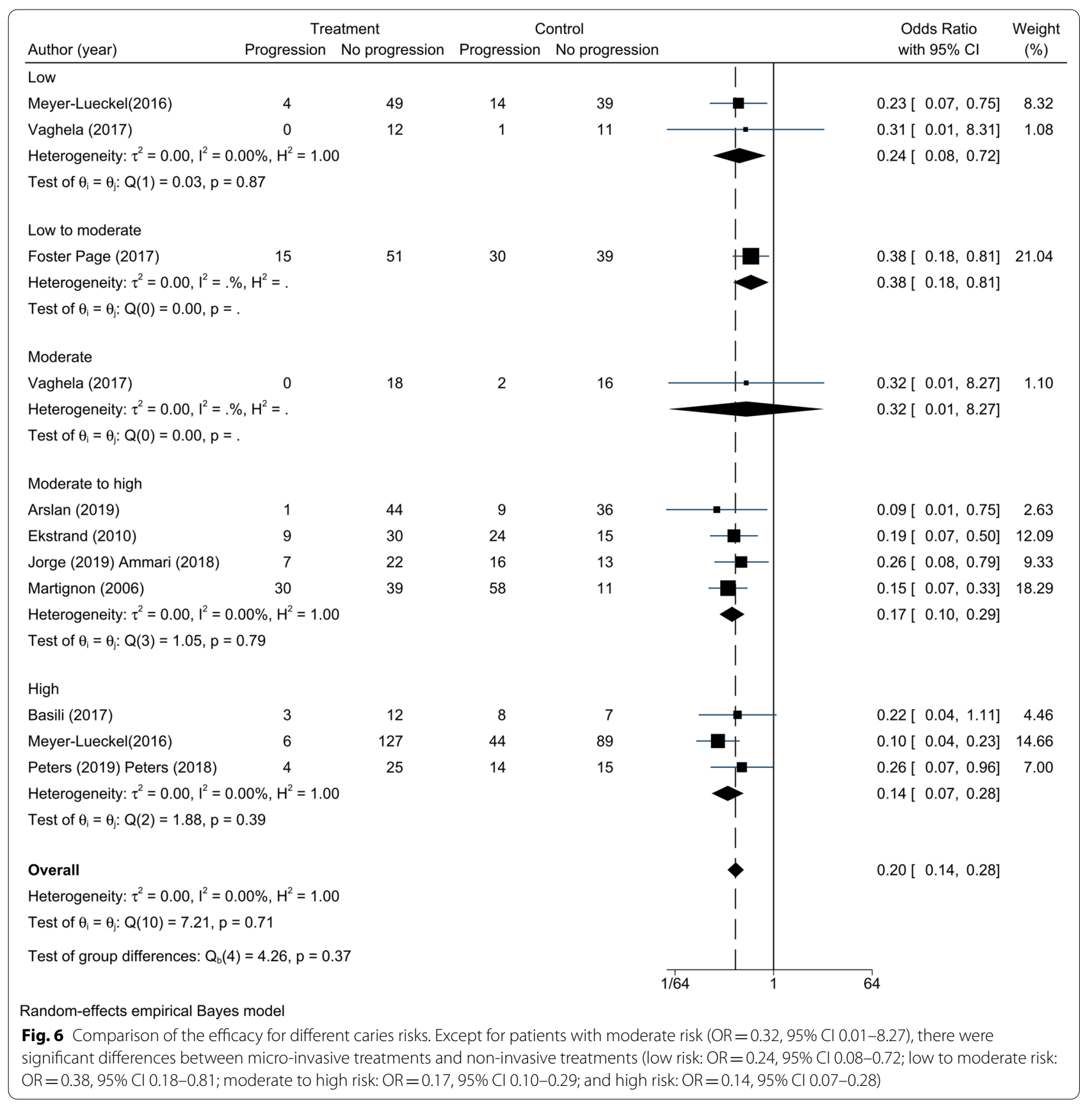

fear but also are efficacious. More studies of primary teeth are warranted to reach more reliable conclusions.

To improve efficiency under different clinical conditions, trials are conducted in terms of patients with different caries risk levels. A previous review indicated that the progression rate of non-cavitated proximal lesions was highly relevant to the individual caries risk [64]. Thus, conducting a caries risk assessment beforehand is vital and should be considered a prerequisite. A caries risk assessment would help in caries management and oral care plans $[65,66]$. In most of the included studies, caries risk levels were evaluated based on the Cariogram or modified Cariogram. Cariogram is a frequently used multifactorial risk assessment model for individuals [67]. Generally, caries risk ranges from low to high. A high caries risk means greater likelihood of being infected with new caries, a higher frequency for preventive instruction, as well as the application of fluoride, and a higher possibility of needing restoration [68]. Therefore, to elucidate the relationship between the caries risk 


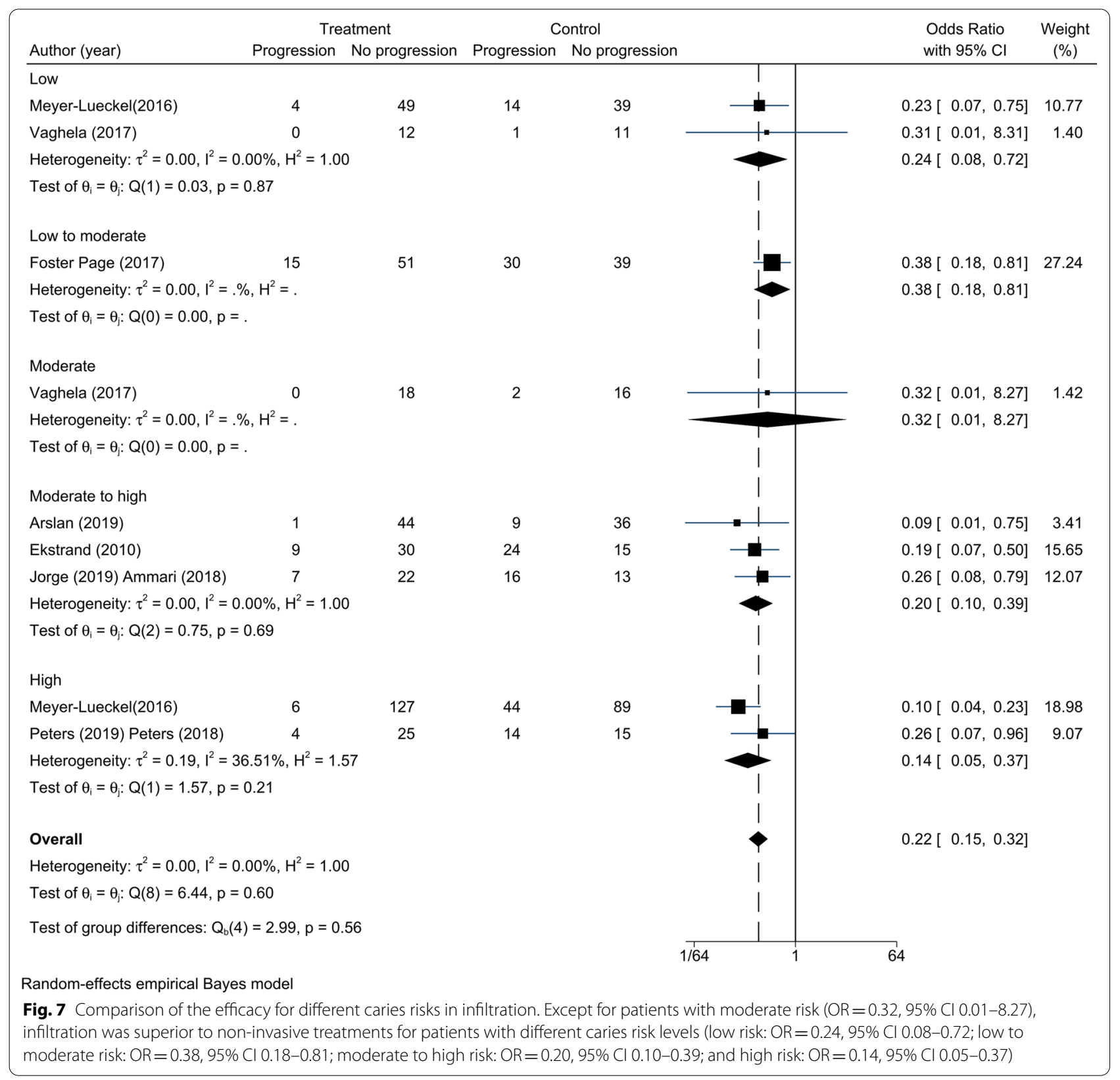

levels and the efficacy of micro-invasive treatments, we divided the enrolled patients into four groups and then conducted subgroup analyses. Previously, four studies concluded that caries progression was not related to the caries risk levels at baseline $[42,45,51,69]$. However, one study concluded that, in children with moderate caries risk, lesion progression was 4 times higher than that in children with low caries risk [47]. In addition, one study demonstrated that there was a moderate relationship between increasing caries risk and lesion progression [27]. In this research, it was shown that micro-invasive treatments could effectively halt caries progression at most caries risk levels. Nevertheless, patients with low caries risk are expected to have slower caries progression [47] and to require more preventive treatments, compared to therapeutic protocols to halt caries progression [33, 57]. Non-invasive treatments are regarded as ethical and should be considered part of the treatment plan, especially when the disease process is controlled [44, 70]. However, patients might refuse non-invasive treatments and favour invasive treatments under some circumstances [71]. Thus, for patients with proximal caries lesions, micro-invasive treatments seem to be a meaningful and important choice. In addition, the results of 
subgroup analysis with the infiltration group showed the same tendency as the results for the overall effect. Therefore, with a limited number of studies, we concluded that micro-invasive treatments could be effective options.

This study showed some strengths that enhance its reliability. To the best of our knowledge, this study was the first to evaluate the efficiency of micro-invasive treatments based on different caries risk levels. In addition, there were more studies in this review than in previously published reviews. All of the studies were RCTs and had a split-mouth design, which helped to improve the validity of the trials. Furthermore, there was no statistically significant heterogeneity among the enrolled studies.

Nevertheless, this review also had some limitations that should be mentioned. First, as a consequence of the limited numbers of studies, patients were divided into rough groups, and each group presented the majority of the caries risk levels in the samples. For further research, it is necessary to determine caries risk levels for every patient and to perform a detailed and precise assessment. Second, the outcome assessment of the included studies varied among independent reading, pairwise reading, and DSR. A standardised method would have been better for outcome evaluation. Otherwise, with a sufficient number of included studies, researchers could conduct subgroup analysis according to the different methods of radiographic assessment, as previously reported [13]. Third, most of the studies had moderate to high risk of bias due to the deviations from intended interventions. One reason was that the blinding of patients is feasible through placebo treatment, yet the blinding of operators is difficult to arrange. The other reason was that most of the included studies were calculated with per-protocol analysis; however, some studies have argued that, in the split-mouth design, it is doubtful whether attrition will affect the overall risk of bias $[13,27]$. Thus to qualify the studies, when the drop-out rate was more than $25 \%$, the missing data were regarded to have potential impacts on the results [13, 31]. Finally, the lack of pre-registration of the this study would be of great risk since the same type of meta-analysis would be published repeatedly.

\section{Conclusions}

In summary, infiltration and sealing were more efficacious than non-invasive treatments for arresting the progression of proximal carious lesions. In both the primary and permanent dentition, infiltration and sealing were effective. For the intervention effects of infiltration or sealing on different caries risk levels, a larger number of trials and more detailed trials are needed for further exploration. For future studies, investigations into the efficacy, feasibility and cost-effectiveness of infiltration versus sealing remain necessary.

\section{Abbreviations \\ OR: Odds ratio; RCTs: Randomised controlled trials.}

\section{Acknowledgements}

Not applicable.

\section{Authors' contributions}

Two authors (Y.C. and D.C.) independently read and assessed the abstracts and selected the articles using the full text for this systematic review. Y.C. contributed substantially to writing the manuscript and performed meta-analysis statistics. L.H. was in charge of the medical descriptions. All authors have read and approved the final manuscript.

\section{Funding}

Not applicable.

\section{Availability of data and materials}

All data generated or analysed during this study are included in this published article [and its supplementary information files]

Ethics approval and consent to participate Not applicable

\section{Consent for publication}

Not applicable

\section{Competing interests}

The authors declare that they have no competing interests.

\section{Author details}

${ }^{1}$ Hospital of Stomatology, Guangdong Provincial Key Laboratory of Stomatology, Sun Yat-Sen University, Guangzhou, China. ${ }^{2}$ Department of Orthodontics, Hospital of Stomatology, Guanghua School of Stomatology, Sun Yat-Sen University, Guangzhou, China. ${ }^{3}$ Department of Preventive Dentistry, Hospital of Stomatology, Guanghua School of Stomatology, Sun Yat-Sen University, Guangzhou, China. ${ }^{4}$ Guangdong Key Laboratory for Dental Disease Prevention and Control, Sun Yat-Sen University, Guangzhou, China.

\section{Appendix 1: Search strategy of databases (search date: 4.6, 2020)}

Cochrane trials

\begin{tabular}{|c|c|}
\hline & $\begin{array}{l}\text { tooth demineralization in Title Abstract Keyword OR } \\
\text { tooth decay in Title Abstract Keyword OR caries in Title } \\
\text { Abstract Keyword OR lesion in Title Abstract Keyword } \\
\text { (Word variations have been searched) }\end{array}$ \\
\hline \#2 & $\begin{array}{l}\text { seal in Title Abstract Keyword OR sealant in Title Abstract } \\
\text { Keyword OR sealing in Title Abstract Keyword OR } \\
\text { infiltrate in Title Abstract Keyword OR infiltration in } \\
\text { Title Abstract Keyword (Word variations have been } \\
\text { searched) }\end{array}$ \\
\hline & $\begin{array}{l}\text { proximal in Title Abstract Keyword OR approximal in Title } \\
\text { Abstract Keyword }\end{array}$ \\
\hline & \#1 AND \#2 AND \#3 \\
\hline
\end{tabular}


Pubmed

\begin{tabular}{|c|c|c|}
\hline$\# 1$ & $\begin{array}{l}\text { Search ((((tooth demineralization[Title/Abstract]) } \\
\text { OR tooth decay[Title/Abstract]) OR caries[Title/ } \\
\text { Abstract]) OR lesion[Title/Abstract]) OR tooth } \\
\text { demineralization[MeSH Terms] }\end{array}$ & 380756 \\
\hline$\# 2$ & $\begin{array}{l}\text { Search ((((sealant[Title/Abstract]) OR seal[Title/ } \\
\text { Abstract]) OR sealing[Title/Abstract]) OR } \\
\text { infiltrate[Title/Abstract]) OR infiltration[Title/ } \\
\text { Abstract] }\end{array}$ & 169858 \\
\hline$\# 3$ & $\begin{array}{l}\text { Search (((proximal[Title/Abstract]) OR } \\
\text { approximal[Title/Abstract]) }\end{array}$ & 2095147 \\
\hline$\# 4$ & $\begin{array}{l}\text { Search (((((()tooth demineralization[Title/ } \\
\text { Abstract]) OR tooth decay[Title/Abstract]) OR } \\
\text { caries[Title/Abstract]) OR lesion[Title/Abstract]) } \\
\text { OR tooth demineralization[MeSH Terms])) AND } \\
\text { (((((sealant[Title/Abstract]) OR seal[Title/Abstract]) } \\
\text { OR sealing[Title/Abstract]) OR infiltrate[Title/ } \\
\text { Abstract]) OR infiltration[Title/Abstract])) AND } \\
\text { ((proximal[Title/Abstract]) OR approximal[Title/ } \\
\text { Abstract]) }\end{array}$ & 304 \\
\hline
\end{tabular}

Embase

\begin{tabular}{|c|c|c|}
\hline$\# 1$ & $\begin{array}{l}\text { 'caries':ab,ti OR 'tooth decay':ab,ti OR 'lesion':ab,ti OR } \\
\text { 'tooth demineralization':ab,ti }\end{array}$ & 503489 \\
\hline \#2 & proximal:ab,ti OR approximal:ab,ti & 275661 \\
\hline \#3 & $\begin{array}{l}\text { seal:ab,ti OR sealing:ab,ti OR sealant:ab,ti OR infiltrate:ab,ti } \\
\text { OR infiltration:ab,ti }\end{array}$ & 240444 \\
\hline & \#1 AND \#2 AND \#3 & 510 \\
\hline
\end{tabular}

\section{Open grey}

$\begin{array}{ll}\text { infiltration AND proximal } & 5 \\ \text { infiltration AND approximal } & 0 \\ \text { infiltrate AND proximal } & 1 \\ \text { infiltrate AND approximal } & 0 \\ \text { seal AND proximal } & 0 \\ \text { seal AND approximal } & 0 \\ \text { sealant AND proximal } & 0 \\ \text { sealant AND approximal } & 0 \\ \text { sealing AND proximal } & 0 \\ \text { sealing AND approximal } & 0 \\ \text { Total } & 6\end{array}$

\section{ProQuest dissertations \& theses global}

all(tooth demineralization OR tooth decay OR caries OR lesion) AND all(approximate OR proximal) AND all(seal* OR infiltrat*)

Web of Science Conference Proceedings Citation IndexScience (CPCI-S)-2000-10.132020

\begin{tabular}{llr}
\hline$\# 1$ & $\begin{array}{l}\text { tooth demineralization OR tooth decay OR caries OR } \\
\text { lesion }\end{array}$ & 49007 \\
$\# 2$ & proximal OR approximal & 11892 \\
$\# 3$ & infiltrat* OR seal* & 34196 \\
$\# 4$ & \#1 AND \#2 AND \#3 & 15 \\
\hline
\end{tabular}

\section{Appendix 2.1: Interactive SoF of the included studies} Quality of evidence evaluated by GRADEpro (online software)

\begin{tabular}{|c|c|c|c|c|c|}
\hline \multirow[t]{2}{*}{ Outcomes } & \multirow{2}{*}{$\begin{array}{l}\text { Plain language } \\
\text { statements }\end{array}$} & \multicolumn{2}{|l|}{ Absolute effect } & \multirow{2}{*}{$\begin{array}{l}\text { Relative effect } \\
(95 \% \mathrm{Cl})\end{array}$} & \multirow{2}{*}{$\begin{array}{l}\text { Certainty of the evidence } \\
\text { GRADE }\end{array}$} \\
\hline & & $\begin{array}{l}\text { With non-invasive } \\
\text { treatments }\end{array}$ & $\begin{array}{l}\text { With micro-invasive } \\
\text { treatments }\end{array}$ & & \\
\hline \multirow[t]{2}{*}{ Measures } & \multirow{2}{*}{$\begin{array}{l}\text { Lesions progression } \\
\text { after infiltration or } \\
\text { sealing }\end{array}$} & 432 & 149 & \multirow{2}{*}{$\begin{array}{l}\text { OR:0.23 } \\
\quad(0.18-0.30)\end{array}$} & \multirow[t]{2}{*}{$\oplus \oplus \oplus \bigcirc$ moderate } \\
\hline & & \multicolumn{2}{|c|}{$\begin{array}{l}283 \text { fewer per } 1000 \text { patients (95\% Cl 312-246 } \\
\text { fewer per } 1000 \text { patients) }\end{array}$} & & \\
\hline \multirow[t]{2}{*}{ Measures: infiltration } & \multirow{2}{*}{$\begin{array}{l}\text { Lesions progression } \\
\text { after infiltration }\end{array}$} & 396 & 121 & \multirow{2}{*}{$\begin{array}{l}\text { OR:0.21 } \\
\quad(0.15-0.29)\end{array}$} & \multirow[t]{2}{*}{$\oplus \oplus \oplus \bigcirc$ moderate } \\
\hline & & \multicolumn{2}{|c|}{$\begin{array}{l}275 \text { fewer per } 1000 \text { patients ( } 95 \% \text { Cl 306-236 } \\
\text { fewer per } 1000 \text { patients) }\end{array}$} & & \\
\hline \multirow[t]{2}{*}{ Measures: sealing } & \multirow{2}{*}{$\begin{array}{l}\text { Lesions progression } \\
\text { after sealing }\end{array}$} & 502 & 214 & \multirow{2}{*}{$\begin{array}{l}\text { OR:0.27 } \\
\quad(0.18-0.42)\end{array}$} & \multirow[t]{2}{*}{$\oplus \oplus \oplus \bigcirc$ moderate } \\
\hline & & \multicolumn{2}{|c|}{$\begin{array}{l}288 \text { fewer per } 1000 \text { patients ( } 95 \% \text { Cl 348-205 } \\
\text { fewer per } 1000 \text { patients) }\end{array}$} & & \\
\hline
\end{tabular}




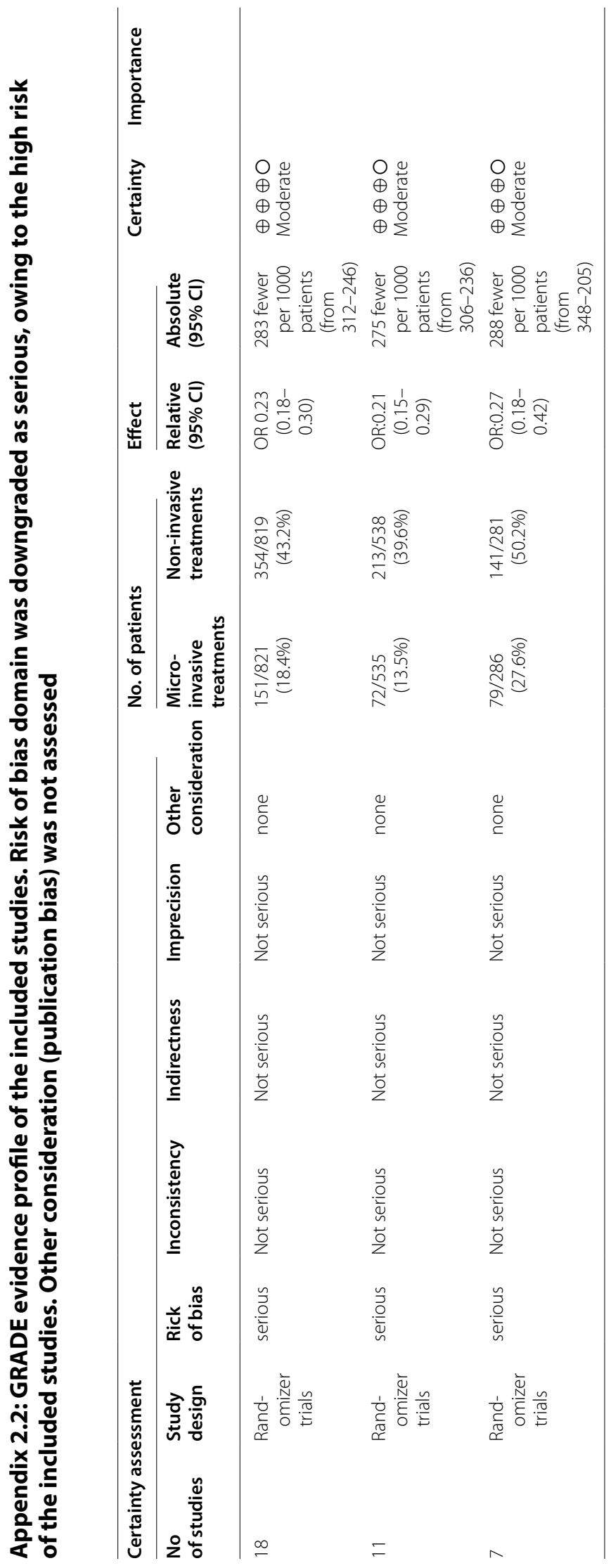


Appendix 3: PRISMA 2009 Checklist

\begin{tabular}{|c|c|c|c|}
\hline Section/topic & $\#$ & Checklist item & $\begin{array}{l}\text { Reported } \\
\text { on page \# }\end{array}$ \\
\hline \multicolumn{4}{|l|}{ Title } \\
\hline Title & 1 & $\begin{array}{l}\text { Identify the report as a } \\
\text { systematic review, meta- } \\
\text { analysis, or both }\end{array}$ & 1 \\
\hline \multicolumn{4}{|l|}{ Abstract } \\
\hline Structured summary & 2 & $\begin{array}{l}\text { Provide a structured } \\
\text { summary including, } \\
\text { as applicable: back- } \\
\text { ground; objectives; data } \\
\text { sources; study eligibility } \\
\text { criteria, participants, } \\
\text { and interventions; study } \\
\text { appraisal and synthesis } \\
\text { methods; results; limita- } \\
\text { tions; conclusions and } \\
\text { implications of key find- } \\
\text { ings; systematic review } \\
\text { registration number }\end{array}$ & $1-2$ \\
\hline \multicolumn{4}{|l|}{ Introduction } \\
\hline Rationale & 3 & $\begin{array}{l}\text { Describe the rationale for } \\
\text { the review in the context } \\
\text { of what is already known }\end{array}$ & $2-4$ \\
\hline Objectives & 4 & $\begin{array}{l}\text { Provide an explicit state- } \\
\text { ment of questions being } \\
\text { addressed with reference } \\
\text { to participants, interven- } \\
\text { tions, comparisons, } \\
\text { outcomes, and study } \\
\text { design (PICOS) }\end{array}$ & 4 \\
\hline \multicolumn{4}{|l|}{ Methods } \\
\hline Protocol and registration & 5 & $\begin{array}{l}\text { Indicate if a review } \\
\text { protocol exists, if and } \\
\text { where it can be accessed } \\
\text { (e.g., Web address), and, } \\
\text { if available, provide } \\
\text { registration information } \\
\text { including registration } \\
\text { number }\end{array}$ & - \\
\hline Eligibility criteria & 6 & $\begin{array}{l}\text { Specify study characteris- } \\
\text { tics (e.g., PICOS, length } \\
\text { of follow-up) and report } \\
\text { characteristics (e.g., years } \\
\text { considered, language, } \\
\text { publication status) used } \\
\text { as criteria for eligibility, } \\
\text { giving rationale }\end{array}$ & $4-5$ \\
\hline Information sources & 7 & $\begin{array}{l}\text { Describe all information } \\
\text { sources (e.g., databases } \\
\text { with dates of cover- } \\
\text { age, contact with study } \\
\text { authors to identify } \\
\text { additional studies) in } \\
\text { the search and date last } \\
\text { searched }\end{array}$ & $5-6$ \\
\hline
\end{tabular}

\begin{tabular}{|c|c|c|c|}
\hline Section/topic & $\#$ & Checklist item & $\begin{array}{l}\text { Reported } \\
\text { on page \# }\end{array}$ \\
\hline Search & 8 & $\begin{array}{l}\text { Present full electronic } \\
\text { search strategy for at } \\
\text { least one database, } \\
\text { including any limits } \\
\text { used, such that it could } \\
\text { be repeated }\end{array}$ & $5-6$ \\
\hline Study selection & 9 & $\begin{array}{l}\text { State the process for } \\
\text { selecting studies (i.e., } \\
\text { screening, eligibility, } \\
\text { included in systematic } \\
\text { review, and, if applicable, } \\
\text { included in the meta- } \\
\text { analysis) }\end{array}$ & $5-6$ \\
\hline Data collection process & 10 & $\begin{array}{l}\text { Describe method of data } \\
\text { extraction from reports } \\
\text { (e.g., piloted forms, inde- } \\
\text { pendently, in duplicate) } \\
\text { and any processes for } \\
\text { obtaining and confirm- } \\
\text { ing data from investiga- } \\
\text { tors }\end{array}$ & 6 \\
\hline Data items & 11 & $\begin{array}{l}\text { List and define all variables } \\
\text { for which data were } \\
\text { sought (e.g., PICOS, } \\
\text { funding sources) and } \\
\text { any assumptions and } \\
\text { simplifications made }\end{array}$ & 6 \\
\hline $\begin{array}{l}\text { Risk of bias in individual } \\
\text { studies }\end{array}$ & 12 & $\begin{array}{l}\text { Describe methods used } \\
\text { for assessing risk of bias } \\
\text { of individual studies } \\
\text { (including specifica- } \\
\text { tion of whether this } \\
\text { was done at the study } \\
\text { or outcome level), and } \\
\text { how this information is } \\
\text { to be used in any data } \\
\text { synthesis }\end{array}$ & 6 \\
\hline Summary measures & 13 & $\begin{array}{l}\text { State the principal sum- } \\
\text { mary measures (e.g., } \\
\text { risk ratio, difference in } \\
\text { means) }\end{array}$ & 7 \\
\hline Synthesis of results & 14 & 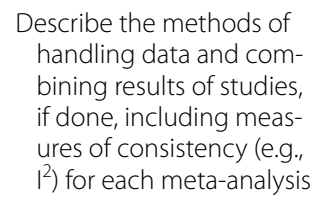 & $6-7$ \\
\hline Section/topic & $\#$ & Checklist item & $\begin{array}{l}\text { Reported } \\
\text { on page \# }\end{array}$ \\
\hline Risk of bias across studies & 15 & $\begin{array}{l}\text { Specify any assessment } \\
\text { of risk of bias that may } \\
\text { affect the cumulative } \\
\text { evidence (e.g., publica- } \\
\text { tion bias, selective } \\
\text { reporting within studies) }\end{array}$ & 7 \\
\hline Additional analyses & 16 & $\begin{array}{l}\text { Describe methods of } \\
\text { additional analyses (e.g., } \\
\text { sensitivity or subgroup } \\
\text { analyses, meta-regres- } \\
\text { sion), if done, indicating } \\
\text { which were pre-spec- } \\
\text { ified }\end{array}$ & $7-8$ \\
\hline
\end{tabular}




\begin{tabular}{|c|c|c|c|}
\hline Section/topic & $\#$ & Checklist item & $\begin{array}{l}\text { Reported } \\
\text { on page \# }\end{array}$ \\
\hline \multicolumn{4}{|l|}{ Results } \\
\hline Study selection & 17 & $\begin{array}{l}\text { Give numbers of studies } \\
\text { screened, assessed for } \\
\text { eligibility, and included } \\
\text { in the review, with } \\
\text { reasons for exclusions at } \\
\text { each stage, ideally with a } \\
\text { flow diagram }\end{array}$ & 8 \\
\hline Study characteristics & 18 & $\begin{array}{l}\text { For each study, present } \\
\text { characteristics for which } \\
\text { data were extracted (e.g., } \\
\text { study size, PICOS, follow- } \\
\text { up period) and provide } \\
\text { the citations }\end{array}$ & $8-9$ \\
\hline Risk of bias within studies & 19 & $\begin{array}{l}\text { Present data on risk of } \\
\text { bias of each study and, if } \\
\text { available, any outcome } \\
\text { level assessment (see } \\
\text { item 12) }\end{array}$ & 9 \\
\hline $\begin{array}{l}\text { Results of individual } \\
\text { studies }\end{array}$ & 20 & $\begin{array}{l}\text { For all outcomes consid- } \\
\text { ered (benefits or harms), } \\
\text { present, for each study: } \\
\text { (a) simple summary data } \\
\text { for each intervention } \\
\text { group (b) effect esti- } \\
\text { mates and confidence } \\
\text { intervals, ideally with a } \\
\text { forest plot }\end{array}$ & $10-11$ \\
\hline Synthesis of results & 21 & $\begin{array}{l}\text { Present results of each } \\
\text { meta-analysis done, } \\
\text { including confidence } \\
\text { intervals and measures } \\
\text { of consistency }\end{array}$ & $10-12$ \\
\hline Risk of bias across studies & 22 & $\begin{array}{l}\text { Present results of any } \\
\text { assessment of risk of } \\
\text { bias across studies (see } \\
\text { Item 15) }\end{array}$ & 12 \\
\hline Additional analysis & 23 & $\begin{array}{l}\text { Give results of additional } \\
\text { analyses, if done (e.g., } \\
\text { sensitivity or subgroup } \\
\text { analyses, meta-regres- } \\
\text { sion [see Item 16]) }\end{array}$ & $10-12$ \\
\hline \multicolumn{4}{|l|}{ Discussion } \\
\hline Summary of evidence & 24 & $\begin{array}{l}\text { Summarize the main } \\
\text { findings including the } \\
\text { strength of evidence } \\
\text { for each main outcome; } \\
\text { consider their relevance } \\
\text { to key groups (e.g., } \\
\text { healthcare providers, } \\
\text { users, and policy makers) }\end{array}$ & $12-15$ \\
\hline Limitations & 25 & $\begin{array}{l}\text { Discuss limitations at } \\
\text { study and outcome } \\
\text { level (e.g., risk of bias), } \\
\text { and at review-level (e.g., } \\
\text { incomplete retrieval } \\
\text { of identified research, } \\
\text { reporting bias) }\end{array}$ & $15-16$ \\
\hline Conclusions & 26 & $\begin{array}{l}\text { Provide a general interpre- } \\
\text { tation of the results in } \\
\text { the context of other evi- } \\
\text { dence, and implications } \\
\text { for future research }\end{array}$ & 16 \\
\hline
\end{tabular}

\begin{tabular}{lcc}
\hline Section/topic & $\#$ Checklist item & $\begin{array}{c}\text { Reported } \\
\text { on page \# }\end{array}$ \\
\hline Funding & $27 \begin{array}{l}\text { Describe sources of fund- } \\
\text { ing for the systematic } \\
\text { review and other sup- } \\
\text { port (e.g., supply of data); } \\
\text { role of funders for the } \\
\text { systematic review }\end{array}$ \\
\hline
\end{tabular}

\section{From: Moher et al. [36]}

For more information, visit: www.prisma-statement.org

Received: 12 August 2020 Accepted: 10 December 2020

Published online: 07 January 2021

\section{References}

1. Kassebaum NJ, Smith AGC, Bernabe E, Fleming TD, Reynolds AE, Vos T, Murray CJL, Marcenes W, Collaborators GBDOH. Global, regional, and national prevalence, incidence, and disability-adjusted life years for oral conditions for 195 countries, 1990-2015: a systematic analysis for the global burden of diseases, injuries, and risk factors. J Dent Res. 2017;96(4):380-7.

2. Chestnutt IG, Schafer F, Jacobson AP, Stephen KW. Incremental susceptibility of individual tooth surfaces to dental caries in Scottish adolescents. Community Dent Oral Epidemiol. 1996;24(1):11-6.

3. Liang Y, Deng Z, Dai X, Tian J, Zhao W. Micro-invasive interventions for managing non-cavitated proximal caries of different depths: a systematic review and meta-analysis. Clin Oral Investig. 2018;22(8):2675-84.

4. Brantley CF, Bader JD, Shugars DA, Nesbit SP. Does the cycle of rerestoration lead to larger restorations? J Am Dent Assoc. 1995;126(10):1407-13.

5. Domejean S, Ducamp R, Leger S, Holmgren C. Resin infiltration of non-cavitated caries lesions: a systematic review. Med Princ Pract. 2015;24(3):216-21.

6. Frencken JE, Peters MC, Manton DJ, Leal SC, Gordan VV, Eden E. Minimal intervention dentistry for managing dental caries - a review: report of a FDI task group. Int Dent J. 2012;62(5):223-43.

7. Schwendicke F, Meyer-Lueckel H, Stolpe M, Dorfer CE, Paris S. Costs and effectiveness of treatment alternatives for proximal caries lesions. PLoS ONE. 2014;9(1):e86992.

8. Schwendicke F, Splieth C, Breschi L, Banerjee A, Fontana M, Paris S, Burrow MF, Crombie F, Page LF, Gaton-Hernandez P, et al. When to intervene in the caries process? An expert Delphi consensus statement. Clin Oral Investig. 2019;23(10):3691-703.

9. Slayton RL, Urquhart O, Araujo MWB, Fontana M, Guzman-Armstrong S, Nascimento MM, Novy BB, Tinanoff N, Weyant RJ, Wolff MS, et al. Evidence-based clinical practice guideline on nonrestorative treatments for carious lesions: a report from the American Dental Association. J Am Dent Assoc. 2018;149(10):837-49.

10. Cochrane NJ, Shen P, Byrne SJ, Walker GD, Adams GG, Yuan Y, Reynolds C, Hoffmann B, Dashper SG, Reynolds EC. Remineralisation by chewing sugar-free gums in a randomised, controlled in situ trial including dietary intake and gauze to promote plaque formation. Caries Res. 2012:46(2):147-55.

11. Cury JA, Tenuta LM. Enamel remineralization: controlling the caries disease or treating early caries lesions? Braz Oral Res. 2009;23(Suppl 1):23-30.

12. Manoharan V, Kumar AS, Arumugam SB, Anand V, Krishnamoorthy S, Methippara JJ. Is resin infiltration a microinvasive approach to white lesions of calcified tooth structures? A systemic review. Int J Clin Pediatr Dent. 2019;12(1):53-8.

13. Dorri M, Dunne SM, Walsh T, Schwendicke F. Micro-invasive interventions for managing proximal dental decay in primary and permanent teeth. Cochrane Db Syst Rev. 2015;11:CD010431. 
14. Schwendicke F, Foster Page LA, Smith LA, Fontana M, Thomson WM, Baker SR. To fill or not to fill: a qualitative cross-country study on dentists' decisions in managing non-cavitated proximal caries lesions. Implement Sci. 2018;13(1):54

15. Chatzimarkou S, Koletsi D, Kavvadia K. The effect of resin infiltration on proximal caries lesions in primary and permanent teeth. A systematic review and meta-analysis of clinical trials. J Dent. 2018;77:8-17.

16. Yoo HK, Kim SH, Kim SI, Shin YS, Shin SJ, Park JW. Seven-year Follow-up of Resin Infiltration Treatment on Noncavitated Proximal Caries. Oper Dent. 2019:44(1):8-12.

17. Ntovas $P$, Rahiotis $C$. A clinical guideline for caries infiltration of proximal enamel lesions with resins. Br Dent J. 2018;225(4):299-304.

18. Meyer-Lueckel H, Paris S. Improved resin infiltration of natural caries lesions. J Dent Res. 2008;87(12):1112-6.

19. Paris S, Meyer-Lueckel H, Kielbassa AM. Resin infiltration of natural caries lesions. J Dent Res. 2007;86(7):662-6.

20. Arslan S, Lipski L, Dubbs K, Elmali F, Ozer F. Effects of different resin sealing therapies on nanoleakage within artificial non-cavitated enamel lesions. Dent Mater J. 2018;37(6):981-7.

21. Gomez S, Uribe S, Onetto JE, Emilson CG. SEM analysis of sealant penetration in posterior approximal enamel carious lesions in vivo. J Adhes Dent. 2008;10(2):151-6.

22. Gomez SS, Onetto JE, Uribe SA, Emilson CG. Therapeutic seal of approximal incipient noncavitated carious lesions: technique and case reports. Quintessence Int. 2007;38(2):e99-105.

23. Alkilzy M, Berndt C, Meller C, Schidlowski M, Splieth C. Sealing of proximal surfaces with polyurethane tape: a two-year clinical and radiographic feasibility study. J Adhes Dent. 2009;11(2):91-4

24. Alkilzy M, Berndt C, Splieth CH. Sealing proximal surfaces with polyurethane tape: three-year evaluation. Clin Oral Investig. 2011;15(6):879-84.

25. Basili CP, Emilson CG, Corvalan GC, Moran MP, Torres C, Quiroz MD, Gomez SS. Preventive and therapeutic proximal sealing: a 3.5-year randomized controlled clinical trial follow-up. Caries Res. 2017;51(4):387-93.

26. Gomez SS, Basili CP, Emilson CG. A 2-year clinical evaluation of sealed noncavitated approximal posterior carious lesions in adolescents. Clin Oral Investig. 2005;9(4):239-43.

27. Martignon S, Tellez M, Santamaria RM, Gomez J, Ekstrand KR. Sealing dis tal proximal caries lesions in first primary molars: efficacy after 2.5 years. Caries Res. 2010;44(6):562-70.

28. Trairatvorakul C, Itsaraviriyakul S, Wiboonchan W. Effect of glassionomer cement on the progression of proximal caries. J Dent Res. 2011:90(1):99-103.

29. Mickenautsch S, Yengopal V. Validity of sealant retention as surrogate for caries prevention —a systematic review. PLoS ONE. 2013;8(10):e77103.

30. Ammari MM, Soviero VM, da Silva Fidalgo TK, Lenzi M, Ferreira DM, Mattos CT, de Souza IP, Maia LC. Is non-cavitated proximal lesion sealing an effective method for caries control in primary and permanent teeth? A systematic review and meta-analysis. J Dent. 2014;42(10):1217-27.

31. Elrashid AH, Alshaiji BS, Saleh SA, Zada KA, Baseer MA. Efficacy of resin infiltrate in noncavitated proximal carious lesions: a systematic review and meta-analysis. J Int Soc Prev Community Dent. 2019:9(3):211-8.

32. Krois J, Gostemeyer G, Reda S, Schwendicke F. Sealing or infiltrating proximal carious lesions. J Dent. 2018;74:15-22.

33. Young DA, Featherstone JD. Caries management by risk assessment. Community Dent Oral Epidemiol. 2013;41(1):e53-63.

34. Manhart J, Chen H, Hamm G, Hickel R. Buonocore Memorial Lecture. Review of the clinical survival of direct and indirect restorations in posterior teeth of the permanent dentition. Oper Dent. 2004;29(5):481-508.

35. Hickel R, Kaaden C, Paschos E, Buerkle V, Garcia-Godoy F, Manhart J. Longevity of occlusally-stressed restorations in posterior primary teeth. Am J Dent. 2005;18(3):198-211.

36. Moher D, Liberati A, Tetzlaff J, Altman DG, The PRISMA Group. Preferred reporting items for systematic reviews and meta-analyses: the PRISMA statement. PLoS Med. 2009;6(7):e1000097. https://doi.org/10.1371/journ al.pmed1000097.

37. Liberati A, Altman DG, Tetzlaff J, Mulrow C, Gotzsche PC, loannidis JP, Clarke M, Devereaux PJ, Kleijnen J, Moher D. The PRISMA statement for reporting systematic reviews and meta-analyses of studies that evaluate health care interventions: explanation and elaboration. J Clin Epidemiol. 2009;62(10):e1-34.
38. Sterne JAC, Savovic J, Page MJ, Elbers RG, Blencowe NS, Boutron I, Cates $C J$, Cheng HY, Corbett MS, Eldridge SM, et al. RoB 2: a revised tool for assessing risk of bias in randomised trials. BMJ. 2019;366:14898.

39. Higgins J, Thomas J: Cochrane Handbook for Systematic Reviews of Interventions Version 6.1. The Cochrane Collaboration; 2020.

40. Guyatt GH, Oxman AD, Vist GE, Kunz R, Falck-Ytter Y, Alonso-Coello P. Schunemann HJ, Group GW. GRADE: an emerging consensus on rating quality of evidence and strength of recommendations. BMJ. 2008;336(7650):924-6.

41. Balshem H, Helfand M, Schunemann HJ, Oxman AD, Kunz R, Brozek J, Vist GE, Falck-Ytter Y, Meerpohl J, Norris S, et al. GRADE guidelines: 3 . Rating the quality of evidence. J Clin Epidemiol. 2011;64(4):401-6.

42. Ammari MM, Jorge RC, Souza IPR, Soviero VM. Efficacy of resin infiltration of proximal caries in primary molars: 1-year follow-up of a split-mouth randomized controlled clinical trial. Clin Oral Investig. 2018;22(3):1355-62.

43. Arslan S, Kaplan MH. The effect of resin infiltration on the progression of proximal caries lesions: a randomized clinical trial. Med Princ Pract. 2020;29(3):238-43.

44. Arthur RA, Zenkner JE, d'Ornellas Pereira Junior JC, Correia RT, Alves LS, Maltz M. Proximal carious lesions infiltration-a 3-year follow-up study of a randomized controlled clinical trial. Clin Oral Investig. 2018;22(1):469-74.

45. Bagher SM, Hegazi FM, Finkelman M, Ramesh A, Gowharji N, Swee G, Felemban O, Loo CY. Radiographic effectiveness of resin infiltration in arresting incipient proximal enamel lesions in primary molars. Pediatr Dent. 2018:40(3):195-200.

46. Ekstrand KR, Bakhshandeh A, Martignon S. Treatment of proximal superficial caries lesions on primary molar teeth with resin infiltration and fluoride varnish versus fluoride varnish only: efficacy after 1 year. Caries Res. 2010:44(1):41-6.

47. Foster Page LA, Beckett D, Ahmadi R, Schwass DR, Leon de la Barra S, Moffat SM, Meldrum A, Thomson WM. Resin infiltration of caries in primary molars in a community setting: 24 -month randomized controlled trial findings. JDR Clin Trans Res. 2017;2(3):287-94.

48. Jorge RC, Ammari MM, Soviero VM, Souza IPR. Randomized controlled clinical trial of resin infiltration in primary molars: 2 years follow-up. J Dent. 2019;90:103184.

49. Martignon S, Ekstrand KR, Ellwood R. Efficacy of sealing proximal early active lesions: an 18-month clinical study evaluated by conventional and subtraction radiography. Caries Res. 2006;40(5):382-8.

50. Martignon S, Ekstrand KR, Gomez J, Lara JS, Cortes A. Infiltrating/sealing proximal caries lesions: a 3-year randomized clinical trial. J Dent Res. 2012;91(3):288-92.

51. Meyer-Lueckel H, Balbach A, Schikowsky C, Bitter K, Paris S. Pragmatic RCT on the efficacy of proximal caries infiltration. J Dent Res. 2016;95(5):531-6.

52. Meyer-Lueckel H, Bitter K, Paris S. Randomized controlled clinical trial on proximal caries infiltration: three-year follow-up. Caries Res. 2012:46(6):544-8.

53. Paris S, Bitter K, Krois J, Meyer-Lueckel H. Seven-year-efficacy of proximal caries infiltration—randomized clinical trial. J Dent. 2020;93:103277.

54. Paris $\mathrm{S}$, Hopfenmuller W, Meyer-Lueckel H. Resin infiltration of caries lesions: an efficacy randomized trial. J Dent Res. 2010;89(8):823-6.

55. Peters MC, Hopkins AR Jr, Yu Q. Resin infiltration: an effective adjunct strategy for managing high caries risk - a within-person randomized controlled clinical trial. J Dent. 2018;79:24-30.

56. Peters MC, Hopkins AR Jr, Zhu L, Yu Q. Efficacy of proximal resin infiltration on caries inhibition: results from a 3-year randomized controlled clinical trial. J Dent Res. 2019;98(13):1497-502.

57. Vaghela P: Resin infiltration of incipient interproximal caries: a 6-month randomized, controlled clinical trial. Master theses. The University of Alabama at Birmingham, Science Dentistry; 2017.

58. Altarabulsi MB, Alkilzy M, Splieth CH. Clinical applicability of resin infiltration for proximal caries. Quintessence Int. 2013;44(2):97-104.

59. Schmidlin PR, Sener B, Attin T, Wiegand A. Protection of sound enamel and artificial enamel lesions against demineralisation: caries infiltrant versus adhesive. J Dent. 2012;40(10):851-6.

60. Mueller J, Yang F, Neumann K, Kielbassa AM. Surface tridimensional topography analysis of materials and finishing procedures after resinous infiltration of subsurface bovine enamel lesions. Quintessence Int 2011;42(2):135-47. 
61. Scheibe KG, Almeida KG, Medeiros IS, Costa JF, Alves CM. Effect of different polishing systems on the surface roughness of microhybrid composites. J Appl Oral Sci. 2009;17(1):21-6.

62. Ulrich I, Mueller J, Wolgin M, FrankW, Kielbassa AM. Tridimensional surface roughness analysis after resin infiltration of (deproteinized) natural subsurface carious lesions. Clin Oral Investig. 2015;19(6):1473-83.

63. Weitman RT, Eames WB. Plaque accumulation on composite surfaces after various finising procedures. J Am Dent Assoc. 1975;91(1):101-6.

64. Splieth $\mathrm{CH}$, Kanzow P, Wiegand A, Schmoeckel J, Jablonski-Momeni A How to intervene in the caries process: proximal caries in adolescents and adults - a systematic review and meta-analysis. Clin Oral Investig. 2020;24(5):1623-36.

65. Cagetti MG, Bonta G, Cocco F, Lingstrom P, Strohmenger L, Campus G. Are standardized caries risk assessment models effective in assessing actual caries status and future caries increment? A systematic review. BMC Oral Health. 2018;18(1):123.

66. Domejean S, Banerjee A, Featherstone JDB. Caries risk/susceptibility assessment: its value in minimum intervention oral healthcare. Br Dent J. 2017;223(3):191-7.

67. Bratthall D. G HP: Cariogram - a multifactorial risk assessment model for a multifactorial disease. Community Dent Oral Epidemiol. 2005;33:256-64.
68. Signori C, Laske M, Bronkhorst EM, Huysmans M, Cenci MS, Opdam NJM. Impact of individual-risk factors on caries treatment performed by general dental practitioners. J Dent. 2019;81:85-90.

69. Kabakchieva RI, Gateva NH, Mihaylova HD. Non-operative treatment of non-cavitated approximal carious lesions of permanent Chidren's teeth. J IMAB. 2014;20(5):626-30.

70. Holmgren C, Gaucher C, Decerle N, Domejean S. Minimal intervention dentistry II: part 3. Management of non-cavitated (initial) occlusal caries lesions-non-invasive approaches through remineralisation and therapeutic sealants. Br Dent J. 2014;216(5):237-43.

71. Mitchell ST, Funkhouser E, Gordan WV, Riley JL 3rd, Makhija SK, Litaker MS, Gilbert GH, National Dental PCG. Satisfaction with dental care among patients who receive invasive or non-invasive treatment for non-cavitated early dental caries: findings from one region of the National Dental PBRN. BMC Oral Health. 2017;17(1):70.

\section{Publisher's Note}

Springer Nature remains neutral with regard to jurisdictional claims in published maps and institutional affiliations.
Ready to submit your research? Choose BMC and benefit from:

- fast, convenient online submission

- thorough peer review by experienced researchers in your field

- rapid publication on acceptance

- support for research data, including large and complex data types

- gold Open Access which fosters wider collaboration and increased citations

- maximum visibility for your research: over $100 \mathrm{M}$ website views per year

At BMC, research is always in progress.

Learn more biomedcentral.com/submissions 